\title{
Nordic Health Registry-Based Research: A Review of Health Care Systems and Key Registries
}

\author{
Kristina Laugesen (D) \\ Jonas F Ludvigsson (DD ${ }^{2,3}$ \\ Morten Schmidt (iD) 1,4 \\ Mika Gissler ${ }^{5-7}$ \\ Unnur Anna \\ Valdimarsdottir $\mathbb{D}^{2,8,9}$ \\ Astrid Lunde ${ }^{10}$ \\ Henrik Toft Sørensen (D) ${ }^{1,11}$ \\ 'Department of Clinical Epidemiology, \\ Aarhus University Hospital, Aarhus, \\ Denmark; ${ }^{2}$ Department of Medical \\ Epidemiology and Biostatistics, \\ Karolinska Institutet, Stockholm, Sweden; \\ ${ }^{3}$ Department of Pediatrics, Örebro \\ University Hospital, Örebro, Sweden; \\ ${ }^{4}$ Department of Cardiology, Aarhus \\ University Hospital, Aarhus, Denmark; \\ ${ }^{5}$ Information Services Department, THL \\ Finnish Institute for Health and Welfare, \\ Helsinki, Finland; ${ }^{6}$ Research Centre for \\ Child Psychiatry, University of Turku, \\ Turku, Finland; ' ${ }^{7}$ Department of Molecular \\ Medicine and Surgery, Karolinska \\ Institute, Stockholm, Sweden and Region \\ Stockholm, Academic Primary Health \\ Care Centre, Stockholm, Sweden; \\ ${ }^{8}$ Center of Public Health Science, Faculty \\ of Medicine, University of Iceland, \\ Reykjavik, Iceland; ${ }^{9}$ Department of \\ Epidemiology, Harvard TH Chan School \\ of Public Health, Boston, MA, USA; \\ ${ }^{10}$ Department of Global Public Health \\ and Primary Care, University of Bergen, \\ Bergen, Norway; "'KOR, The Danish \\ Advisory Board on Register Based \\ Research, the Danish e-infrastructure \\ Cooperation, Copenhagen, Denmark
}

Correspondence: Kristina Laugesen

Department of Clinical Epidemiology,

Aarhus University Hospital, Aurhus,

Denmark

Tel +45 87167212

Email Kristina.laugesen@clin.au.dk

\begin{abstract}
The Nordic countries are Denmark, Finland, Iceland, Norway, and Sweden and comprise a total population of approximately 27 million. The countries provide unique opportunities for joint health registry-based research in large populations with long and complete follow-up, facilitated by shared features, such as the tax-funded and public health care systems, the similar population-based registries, and the personal identity number as unique identifier of all citizens. In this review, we provide an introduction to the health care systems, key registries, and how to navigate the practical and ethical aspects of setting up such studies. For each country, we provide an overview of population statistics and health care expenditures, and describe the operational and administrative organization of the health care system. The Nordic registries provide population-based, routine, and prospective data on individuals lives and health with virtually complete follow-up and exact censoring information. We briefly describe the total population registries, birth registries, patient registries, cancer registries, prescription registries, and causes of death registries with a focus on period of coverage, selected key variables, and potential limitations. Lastly, we discuss some practical and legal perspectives. The potential of joint research is not fully exploited, mainly due to legal and practical difficulties in, for example, cross-border sharing of data. Future tasks include clear and transparent legal pathways and a framework by which practical aspects are facilitated.
\end{abstract}

Keywords: health care system, population characteristics, registries, epidemiology, Scandinavian and Nordic countries

\section{Introduction}

The Nordic countries are Denmark, Finland, Iceland, Norway, and Sweden and comprise a total population of approximately 27 million (Figure 1). All five countries have welfare state models with universal and tax-funded health care systems, population-based nationwide registries, and personal identity numbers that enable individuallevel linkage of these registries. The similarities between and within the Nordic registries allow researchers to combine data from several countries into one study cohort. Combining these resources in Nordic health registry-based studies provides unique opportunities for research on large study populations with long and complete follow-up. Such studies may contribute to important research findings, ${ }^{1-6}$ especially regarding rare exposures or outcomes. However, conducting such multinational studies requires in-depth understanding of the respective health care systems and registries, as well as some knowledge of practical and legal matters.

In this review, we provide an overview of all five health care systems, describe key registries, and provide guidance on how to navigate the practical and ethical aspects of setting up Nordic study collaborations. 


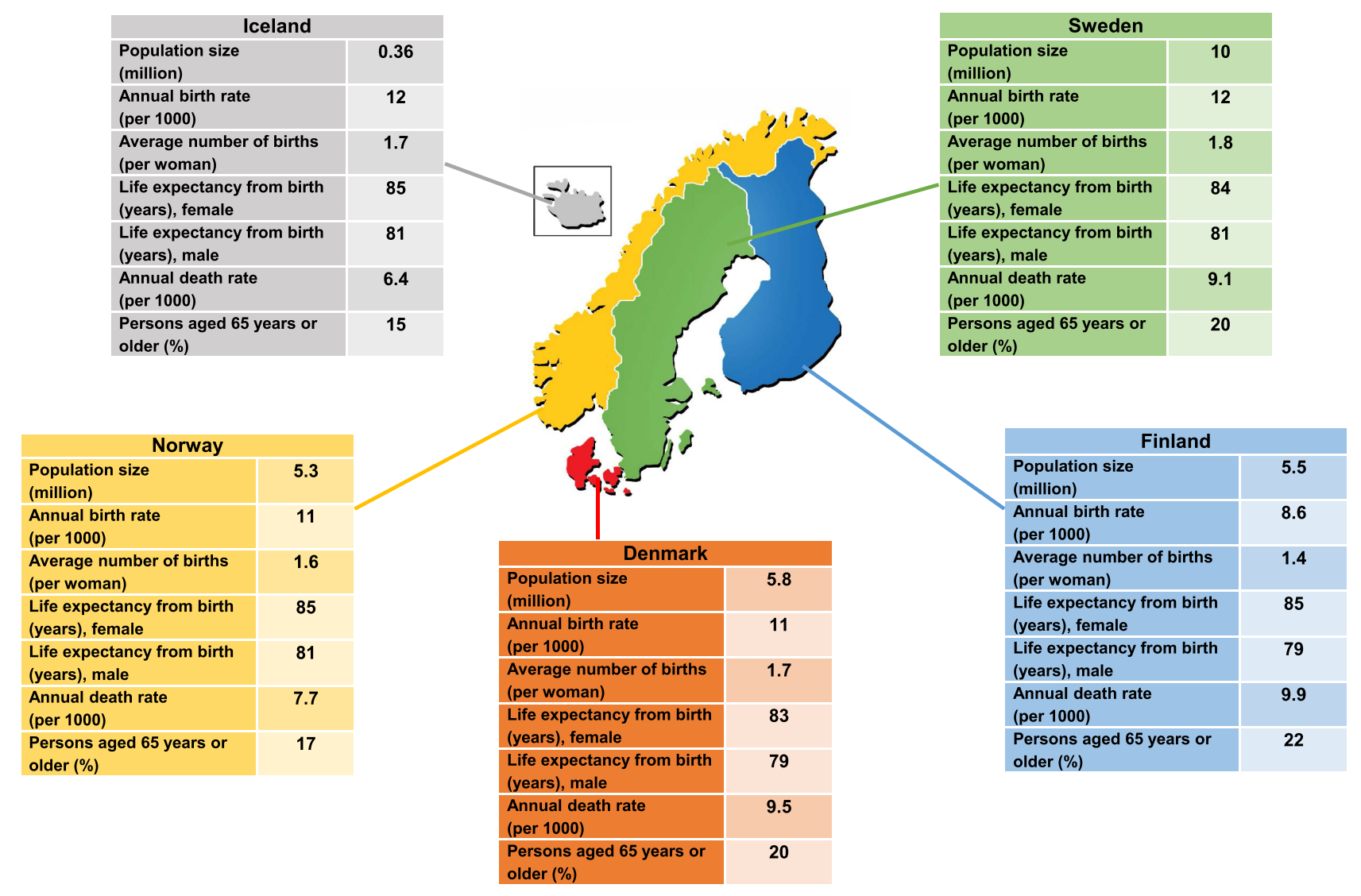

Figure I Population statistics for the five Nordic countries, 2018

Notes: Data from the World Bank (2018).

\section{The Health Care Systems}

People in the Nordic countries have universal access to the health care systems, which are mainly publicly financed through taxes with minor private health care sectors and limited private medical insurance. Approximately $2-10 \%$ of total in-hospital beds are private depending on the country. $^{7-9}$ Moreover, private providers are often reimbursed by the public health insurance system according to economic contracts between the private and public sectors. Below we provide a brief description of each of the Nordic health care systems. More detailed information can be found elsewhere. ${ }^{7-10-14}$

\section{The Danish Health Care System}

Denmark is a country with approximately 5.8 million inhabitants and population statistics as shown in Figure $1 .^{15-18}$ In 2019, Denmark spent approximately $10 \%$ of its gross domestic product (GDP) on health care expenditures, corresponding to 5568 USD per capita (Figure 2). ${ }^{19}$ Roughly $85 \%$ of all health care expenses are covered through taxes, including free access to general practitioners (GPs), hospitals, outpatient hospital specialist clinics, and partial reimbursement of prescribed medications. Patient copayments are $\sim 15 \%$ and primarily consist of cost-sharing for medications, physiotherapy, and/or dental care. $^{7}$ Key health care spending is shown in Figure 2. ${ }^{19,20}$

\section{Operational Organization}

The Danish health care system is subdivided into primary and secondary health care sectors. ${ }^{7}$ Primary health care includes services provided by the regions, such as GPs and private clinics (dentists, psychologists, physiotherapists, chiropractors, and private practicing specialist), as well as services provided by the municipalities, such as elderly care, primary disease prevention, and rehabilitation. The secondary health care sector comprises hospitals, including inpatient treatment, outpatient hospital clinics, and emergency care, as well as psychiatric hospital care.

GPs account for approximately $20 \%(n=4900)$ of the total Danish physician workforce and play a central role in the Danish health care system. ${ }^{7}$ GPs are generalists trained to evaluate the need for referral to specialists. Their 
Health care expenditures

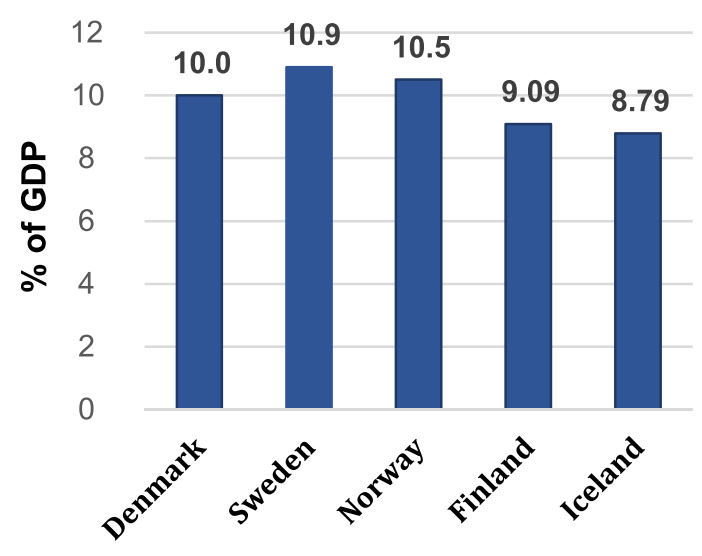

Doctors

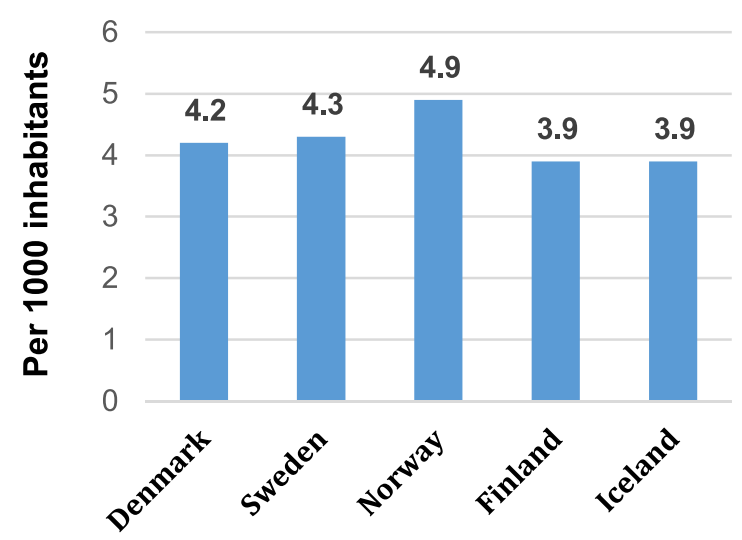

Acute hospital beds

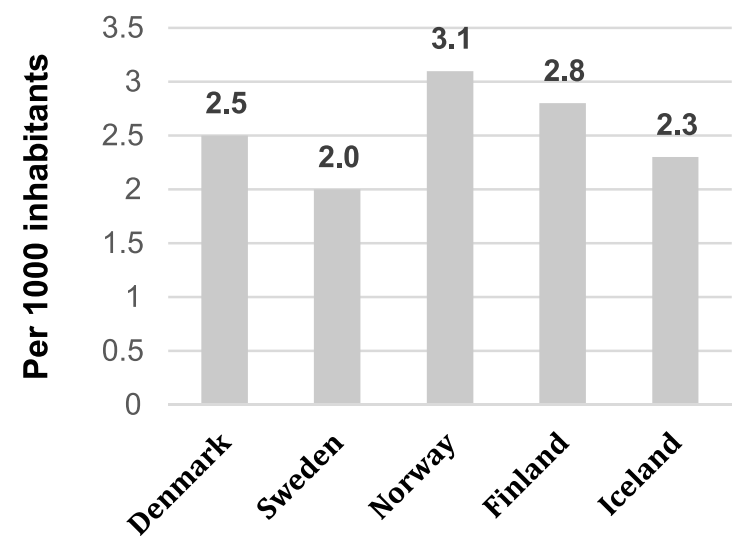

Health care expenditures

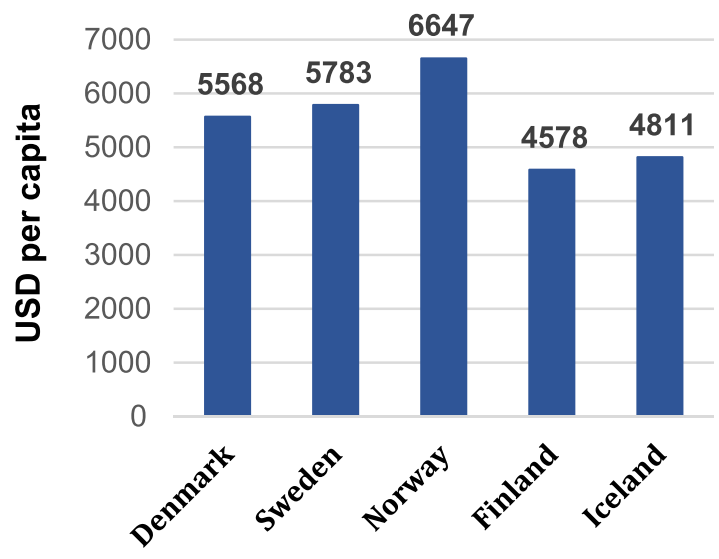

Nurses

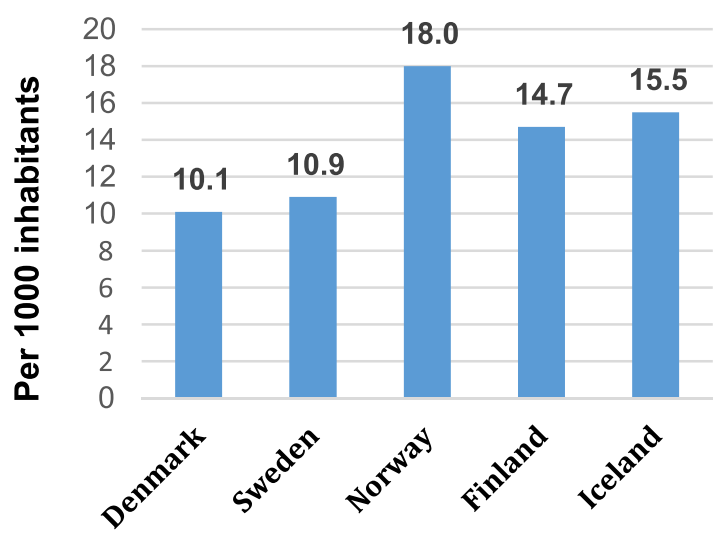

Total hospital beds

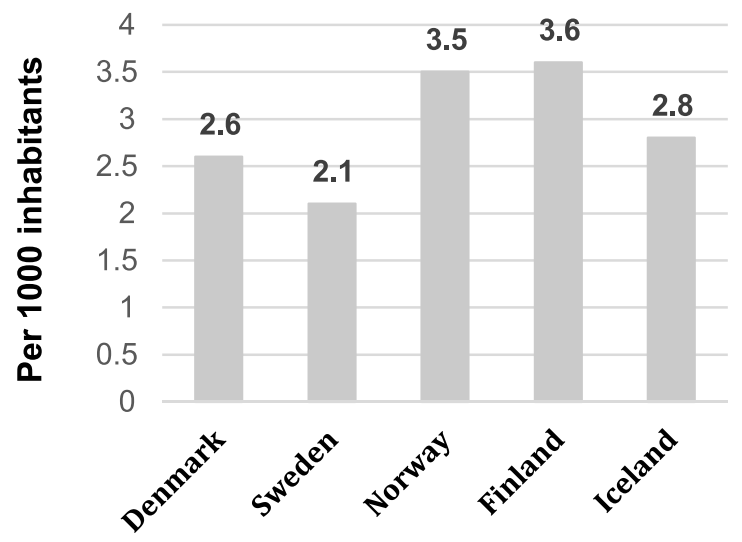

Figure 2 Key spending in the Nordic health care systems, 2018/2019 or latest available.

Notes: Data from OECD. GDP: gross domestic product. Total hospital beds include curative (or acute) care beds, rehabilitative care beds, long-term care beds and other beds in hospitals. The indicator is presented as a total and for curative care and psychiatric care. 


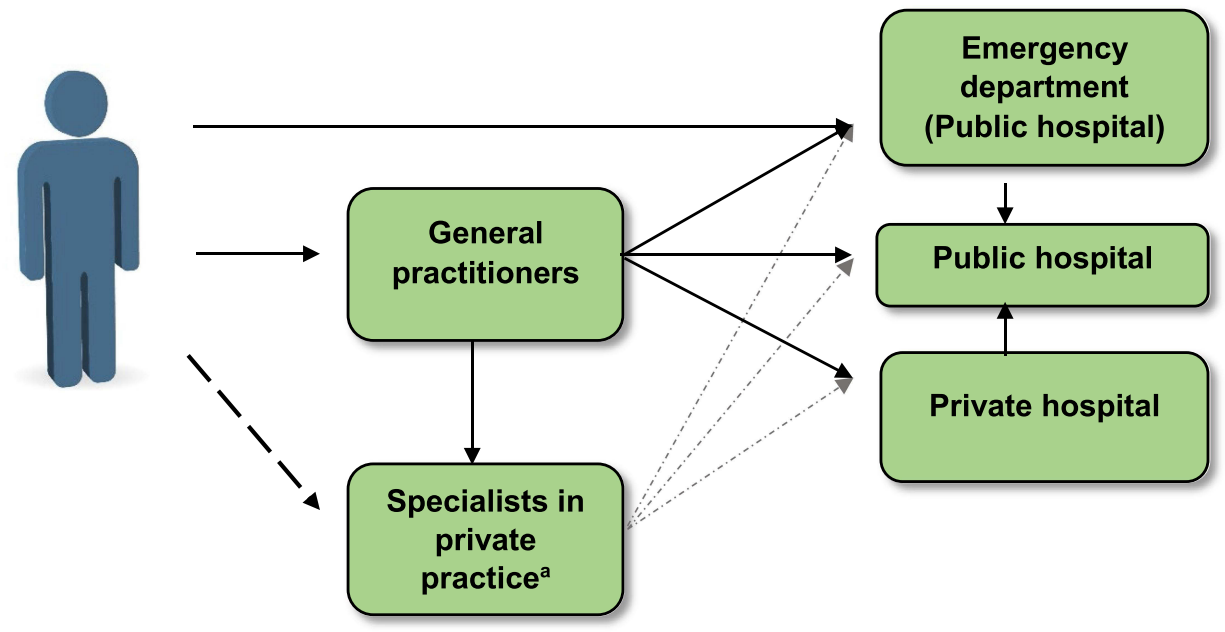

Figure 3 Overview of the operational organization of the Nordic health care systems.

Notes: ancludes physiotherapists, dentists, psychologists, and specialized medical doctors working in private practice as eg. dermatologists, otorhinolaryngologist, fertility treatment specialists, cardiologists and pulmonologists. Visits to dentist never require referral from general practitioners (GPs). Other specialists may be accessed with or without referral from GPs; however, patient co-payment is often larger without a referral. Some private clinics are reimbursed completely or partly by public funding and some rely solely on patient self-payment or private insurance. Specialized medical doctors in private practice can refer patients to hospitals if needed. In Sweden, it is also possible to self-refer to hospital specialists. Patients need to fill out an online form, and then a hospital specialist will decide whether to see the patient without a GP referral.

primary tasks are to treat ordinary health problems, perform regular checkups (eg, children and patients with chronic diseases), prescribe drugs and carry out vaccinations, refer patients to specialists when needed, and follow-up on patient health plans after hospital discharge. Except in emergencies, the GPs are the first point of contact and act as gatekeepers to the hospitals (Figure 3). ${ }^{7}$ GPs further provide on-call services after daily opening hours and on weekends for acute services. In case of emergencies, patients may go directly or by referral to public hospital emergency departments (Figure 3). Private emergency care is not available in Denmark. In 2017, the average number of GP contacts per person was 8 and approximately $85 \%$ of all Danes had at least one contact with their GP. ${ }^{21}$ Danish legislation ensures that diagnosis and treatment are provided within certain timeframes. $^{7}$

\section{Administrative Organization}

The Danish health care system currently has three administrative levels: the national level (state), the regional level (5 regions), and the local level (98 municipalities).

\section{National Level (State)}

The government, headed by The Ministry of Health, defines the framework of the Danish health care system by legislation, national guidelines, and health care monitoring. Furthermore, they set the economic framework and obtain financial agreements between the national, regional, and municipal administrative levels. ${ }^{7}$ The Ministry of Health operates through several authorities or agencies (Supplementary Table 1). ${ }^{7}$ Though the overall health care policy is organized centrally, responsibility for the provision of health care is decentralized.

\section{Regional Level}

The five regions are responsible for GPs, hospitals, specialists in private practice, and specialized nursing homes (eg, psychiatric patients). The regions also administer the Danish Drug Reimbursement Plan. In Denmark, all GPs are private practitioners but work according to a collective economic agreement and are paid by the public health insurance system with no patient cost-sharing (with few exceptions). Most specialists in private practice are also self-employed but are reimbursed for provided services on a fee-for-service basis according to an economic agreement with the regions. ${ }^{7}$ A few private specialists rely solely on patient self-payment or private medical insurance.

\section{Local Level (Municipalities)}

The municipalities are responsible for social services and some health care services, including primary disease prevention and health promotion, student health, child dental 
care, ordinary home care and nursing homes, alcohol and drug abuse treatment, rehabilitation outside hospitals, and postnatal home visits.

\section{The Swedish Health Care System}

Sweden is a country with approximately 10 million inhabitants and population statistics as shown in Figure $1 .{ }^{15-18}$ The Swedish health care system is almost free of charge, with minor visit fees at GPs, outpatient hospital clinics, or during in-hospital stays (Supplementary Table 2) ${ }^{22}$ In 2019 , Sweden spent $10.9 \%$ of their GDP on health care expenditures (5783 USD per capita) (Figure 2). ${ }^{19}$ Tax incomes cover approximately $80 \%$ of the Swedish health care expenses, including services at GPs, hospitals, outpatient specialist clinics, and partial reimbursement of prescribed medications. Patient copayments are $\sim 20 \%$ and include visit fees, as well as copayments for medications, physiotherapy, or dental care. Key health care spending is shown in Figure 2. ${ }^{19,20}$

\section{Operational Organization}

The operational organization of the Swedish health care system is subdivided into primary and secondary health care sectors. The primary health care sector includes GPs, psychologists, physiotherapists, some private practicing specialists, and rehabilitation. The secondary health care sector comprises hospitals, including inpatient and outpatient hospital clinics. ${ }^{11}$

In Sweden, citizens are free to choose their primary care providers. The GPs can be the first point of contact (Figure 3), but citizens also have the opportunity to consult or self-refer to specialists through "1177.se", a 24-hour internet/phone health care service. A large proportion of Swedish patients have their initial health care contact with this service before seeking care with a physical health care provider. Through 1177.se, patients fill out an online or paper form and a specialist then decides whether to see the patient without contact with a GP first. ${ }^{23}$ Approximately $16 \%(n=6000)$ of Swedish physicians work in the primary care setting, ${ }^{24}$ and the average number of yearly GP visits per capita is $1.3 .^{25}$

\section{Administrative Organization}

The Swedish health care system has three administrative levels: the national level (state), regional level (21 counties/regions), and local level (290 municipalities). ${ }^{11}$

\section{National Level (State)}

The state, through the Ministry of Health and Social Affairs, outlines the Swedish health care system by legislation, guidelines, and health care monitoring. ${ }^{11}$ The Ministry of Health and Social Affairs acts through agencies (Supplementary Table 1). ${ }^{11,26}$ Though health care policy is determined centrally, responsibility for providing health care is decentralized and lies within the counties/ regions and municipalities.

\section{Regional Level (Counties/Regions)}

The Swedish counties/regions manage and operate the primary and secondary health care sectors. Primary care is provided by primary care units, approximately $42 \%$ of which are private but mostly still reimbursed by the public health insurance system. ${ }^{27}$ To work as a private practitioner within the social security system, an agreement (including economic agreement) must be made with the County Council. ${ }^{11}$ A number of private digital health care providers recently established themselves in Sweden. Their growth has been spurred, in part, by the COVID19 pandemic. ${ }^{26}$

\section{Local Level (Municipalities)}

The Swedish municipalities are responsible for student health, nursing homes and home care, public health, disease prevention, and rehabilitation. ${ }^{11}$

\section{The Norwegian Health Care System}

Norway is a country with approximately 5.3 million inhabitants and population statistics as shown in Figure 1. ${ }^{15-18}$ The Norwegian health care system is universal with almost free access, though some patient fees exist when visiting GPs or outpatient hospital clinics (Supplementary Table 2). In 2019, Norway spent $10.5 \%$ of their GDP on health care expenditures (6647 USD per capita) (Figure 2). ${ }^{19}$ Tax incomes cover approximately $85 \%$ of all health care expenses, including access to GPs, hospitals, outpatient hospital clinics, and partial reimbursement of prescribed medications. Patient copayments are $\sim 15 \%$ and are primarily copayments for GP or outpatient clinic visits, and medications, or dental care. ${ }^{12}$ Key health care spending is shown in Figure 2. ${ }^{19,20}$

\section{Operational Organization}

The operational organization of the Norwegian health care system is divided into primary and secondary health care sectors. The primary health care sector includes GPs, psychologists, and physiotherapists among others. The secondary health care sector comprises hospitals, including inpatient care, outpatient hospital clinics, and psychiatric health care. GPs account for approximately 16\% $(\mathrm{n}=$ 
$4900)^{28}$ of the total Norwegian physician workforce and have similar tasks as described for Denmark. As in the other Nordic countries, patients need a referral from their GP to access specialized care (eg, hospital outpatient or inpatient care; Figure 3). ${ }^{12}$ In 2019, the average number of GP visits (excluding telephone contacts) per person was 3, and $70 \%$ of all Norwegians had at least one contact with their $\mathrm{GP}^{29}$

Norwegian legislation ensures free hospital choice, which allows patients to be referred for assessment, examination, or treatment by specialists at hospital or treatment centers of their choice, including public or private providers.

\section{Administrative Organization}

The Norwegian health care system is currently organized into three administrative levels: the national level (state), the regional level (4 regional health authorities), and the local level (356 municipalities). A few healthcare responsibilities (eg, dental care) are held by the counties. ${ }^{12}$

\section{National Level (State)}

The state (Ministry of Health and Care Services) determines the national health policy, decides on the allocation of funds within the health sector, and implements the national health policy. The Ministry of Health and Care Services acts through several subordinate institutions (Supplementary Table 1). ${ }^{12,30}$ Furthermore, as the Ministry of Health and Care Services is the owner of the four regional health authorities, the ministry has somewhat direct responsibility for the delivery of hospital and specialist $^{\text {care. }}{ }^{12}$

\section{Regional Level (Health Authorities)}

The four regional health authorities (including 20 hospital trusts) are responsible for the hospitals and specialist outpatient hospital clinics, including psychiatric, rehabilitation and alcohol and substance abuse treatment. ${ }^{12}$

\section{Local Level (Municipalities)}

The Norwegian municipalities are responsible for social services and all primary health care, including GPs, rehabilitation, and physiotherapy, as well as public health and preventive measures. The majority of GPs are selfemployed, but they are embedded in the public system through contracts with the municipalities, and patient cost-sharing is very limited. ${ }^{12}$

\section{The Finnish Health Care System}

Finland is a country with approximately 5.5 million inhabitants and population statistics as shown in Figure $1 .^{15-}$ 18 The Finnish health care system is universal with almost free access, though some fees exist when visiting GPs, emergency rooms, outpatient clinics, or during inpatient hospital stays (Supplementary Table 2). ${ }^{13}$ In 2019, Finland spent $9.1 \%$ of their GDP on health care expenditures (4578 USD per capita) (Figure 2). ${ }^{19}$ Taxes cover approximately $75 \%$ of all health care expenses, including access to GPs, hospitals, outpatient hospital clinics, and partial reimbursement of prescribed medications. Patient copayments are $\sim 20 \%$ and are primarily copayments for visits and procedure fees, medication costs, or dental care. Private insurance covers approximately 5\% of health care expenses. ${ }^{13}$ Key health care spending is shown in Figure 2. ${ }^{19,20}$

\section{Operational Organization}

The operational organization of the Finnish health care system is divided into primary, secondary, and tertiary healthcare. The primary health care sector includes GPs, dentists, psychologists, physiotherapists, some medical specialists, and rehabilitation. In addition, inpatient departments located in primary health centers are a specific feature of Finnish primary care. These inpatient hospitaltype wards are staffed with nurses, GPs, or specialists in geriatrics. The secondary health care sector includes regional hospitals (inpatient and outpatient specialist clinics). The tertiary sector includes university hospitals. GPs account for $\sim 40 \%(n=7000)$ of the total Finnish physician workforce and have similar tasks as described for Denmark. Patients need a referral from their GP to access the hospitals (Figure 3). ${ }^{13}$ In 2019, the average number of visits to health care center per person was 4.1 , of which 1.1 was a GP visit. A total of $67 \%$ of all Finns had used public primary health care in $2019 .{ }^{31}$

\section{Administrative Organization}

The Finnish health care system is currently structured into three administrative levels: the national level (state), the regional level (20 hospital districts), and the local level (311 municipalities). ${ }^{13}$ Finland has a decentralized health care system, meaning that responsibility for organizing, providing, and financing health care lies within the individual municipalities. A future task may be to implement a more centralized system. 


\section{National Level (State)}

The state, headed by the Ministry of Social Affairs and Health, provides a framework for the Finnish health care system via health legislation. ${ }^{13}$ The Ministry of Social Affairs and Health acts through several institutions and agencies (Supplementary Table 1).

\section{Regional and Local Level (Municipalities)}

The municipalities are responsible for organizing, providing, and financing primary care, as well as secondary and tertiary health care services through hospital districts. Due to the decentralized public administration, municipalities decide how the local services are provided, and differences may exist between the municipalities. Primary health care is provided at municipal health centers, where GPs are usually salaried employees of the municipalities. Yet, the lease of physicians from private firms has recently increased. ${ }^{13}$ The country is further divided into 20 hospital districts (plus Åland Islands, an autonomous area with special legislation) that are responsible for the provision of municipal secondary health care services. Hospital districts are federations of municipalities, and each municipality must be a member of a hospital district. Each hospital district is financed and managed by the member municipalities. ${ }^{13}$

\section{The Icelandic Health Care System}

Iceland is a country with approximately 0.36 million inhabitants and population statistics as shown in Figure $1 .^{15-18}$ People in Iceland have almost free access to the health care system with some minor fees for visits to GPs, outpatient hospital clinics and emergency wards (Supplementary Table 2) ${ }^{14}$ In 2019, Iceland spent 8.8\% of their GDP on health care expenditures (4811 USD per capita) (Figure 2). ${ }^{19}$ Tax incomes cover approximately $80 \%$ of the Icelandic health care expenses, including services at GPs, hospitals, outpatient specialist clinics, and partial reimbursement of prescribed medications. Patient copayments are $\sim 20 \%$ and include visit fees and copayments for medications, physiotherapy, or dental care. Key health care spending is shown in Figure 2. ${ }^{19,20}$

\section{Operational Organization}

The Icelandic health care system is divided into primary, secondary, and tertiary health care sectors. The primary health care sector includes GPs and primary health care clinics. The secondary sector includes private practicing specialists and the tertiary health care sector includes hospitals, comprising inpatient and outpatient hospital treatments, as well as psychiatric hospital care. ${ }^{32}$ From 1990-2017, Icelandic GPs had no gatekeeping role, but GP referrals have recently been re-implemented (Figure 3). ${ }^{33}$ GPs account for approximately $17 \%$ of the total Icelandic physician workforce. In 2019, approximately $80 \%$ of the population had contact with GPs (including visits and telephone consultancy) and $74 \%$ of the population actually visited a primary care center/ physician. ${ }^{34}$

\section{Administrative Organization}

The Icelandic health care system is highly state-centralized and divided into a national level (state) and a regional level (7 regions). Local level administration plays a very minor role in the system. ${ }^{14}$

\section{National Level (State)}

The state (the Ministry of Health) is responsible for health policy and the financing, planning, regulation, and delivery of both primary, secondary, and tertiary health care. The Ministry of Health acts through several agencies (Supplementary Table 1). Physicians working in public hospitals and in general practice receive salaries from the state (with some fee-for-service payments to GPs for outof-hours work), as do other professionals (eg, nurses and midwives). Private practitioners, such as medical specialists who provide outpatient care outside of hospitals, physiotherapists, dentists, and psychologists are paid by the state on a fee-for-service basis. ${ }^{14}$

\section{Regional Level}

The country is divided into seven regions for healthcare organization purposes, but these regions have limited administrative authority. ${ }^{14}$

\section{Future Aspects of the Nordic Health Care Systems}

The Nordic countries face several challenges that may strain the existing health care systems in the future, not least from an economic perspective. Foremost among these challenges is the aging population, which has a high demand for healthcare. Simultaneously, the aging population fosters a decline in the workforce and tax payments that are needed to preserve the public health care systems. The proportion of individuals aged $\geq 65$ years has increased substantially in the Nordic countries in recent years; between 1965 and 2019, the proportion of individuals aged $\geq 65$ years has increased from $\sim 11 \%$ to 
$20 \%$ in Denmark, ${ }^{35}$ from $13 \%$ to $20 \%$ in Sweden, ${ }^{36}$ from $12 \%$ to $17 \%$ in Norway, ${ }^{37}$ from $8 \%$ to $22 \%$ in Finland, ${ }^{38}$ and from $8 \%$ to $15 \%$ in Iceland. ${ }^{39}$ With aging populations, the burden of diseases such as cardiovascular diseases, cancer, chronic obstructive pulmonary disease, osteoporosis, diabetes, and dementia increases, as does the burden of multi-morbidity. ${ }^{40}$ In addition, elderly patients with multimorbidity require a substantial joint effort between hospital specialties, as well as between GPs, hospitals, rehabilitation, home care, and nursing homes. The increase in disease burden and multi-morbidity, together with an increase in drug utilization, strains the health care systems and economies. The proportion of migrants in the Nordic populations has increased over the past decades. While migrants typically promote a growing labor force and counteract the aging population, they can also influence health care utilization. It is documented that the health status of migrants differs from that of non-migrants. ${ }^{41,42}$ Migrants may originate from countries without vaccination programs, with poor quality of primary prevention, diet options, and employment conditions as well as high level of trauma exposure and mental distress with the implications of disease development. ${ }^{41,42}$ Further, language and cultural barriers or different health beliefs or attitudes may lead to miscommunication between patients and health care providers with the result of poor health care service and patient dissatisfaction as well as non-compliance. This potential problem is despite the fact that interpreter services are heavily applied. Last, new technologies, used for diagnostic or treatment purposes, as well as novel and effective but expensive drugs place additional pressure on health care economies. Though the advent of biological treatment has revolutionized the care of some patients, such as those with rheumatoid arthritis and inflammatory bowel disease, these treatments and some novel drugs against cancer and inborn errors of metabolism have high costs. $^{43}$ Therefore, prioritizing is becoming more important.

Over the past decades, the Nordic countries have faced a shift from inpatient care to outpatient and primary care, or even home-assisted care, in part to ease the strain on the health care systems, but also for the benefit of the patients. Between 2007 and 2018, the total number of hospital beds per 1000 inhabitants declined from 3.7 to 2.4 in Denmark, from 2.9 to 2.1 in Sweden, from 4.9 to 3.5 in Norway, from 6.7 to 3.6 in Finland, and from 4.1 to 2.9 in Iceland. ${ }^{44}$ Moreover, digital healthcare is quickly growing in all the Nordic countries. However, despite these initiatives, health care expenditures have kept growing. ${ }^{45}$

\section{Concluding Remarks}

All five Nordic countries have welfare state models with tax-funded health care systems and minor private health care sectors. The operational organizations are to some extent similar in the countries, although differences do remain. A shared feature of all five Nordic countries is the GP gatekeeping role, meaning that patients need referral from GPs to access the hospitals . However, in Sweden, GP gatekeeping is only partial. The future challenges of the Nordic health care systems are the aging population, with an increasing demand for health care. Further, novel, effective but expensive technologies and treatments place additional pressure on the health care economies. Hence, prioritizing and individual-tailored treatments are important aspects of the future health care systems. Finally, all five health care systems deliver routinely collected data to a great amount of registries and databases.

\section{The Personal Identity Number and Population-Based Registries}

\section{The Personal Identity Number}

In each of the five Nordic countries, each resident is assigned a unique personal identity number upon birth or immigration, and the number follows each person their whole lifespan (except in under certain circumstances such as gender reassignment). The numbers are typically 10 or 11 digits long and encode the date of birth and sex, as well as a unique identifier. The overall purpose is administrative, and the number is generally used in all aspects of life, such as by authorities, the health care systems, schools and universities, banks and insurance companies, and when applying for jobs, among other examples. ${ }^{46-48}$ The personal identity numbers were originally introduced to control and monitor tax payments and have existed since 1968 in Denmark, ${ }^{46} 1964 / 1968$ in Finland, 1964 in Norway, 1954 in Iceland (1987 in its current form $),{ }^{49}$ and 1947 in Sweden. ${ }^{47}$ From the perspective of registry-based research, these personal identity numbers are essential because they are key identifiers in all registries and databases, enabling easy, accurate, and unambiguous individual-level linkage of the registries. Therefore, these identifiers are essential for using the registries to their full potential (Figure 4). 


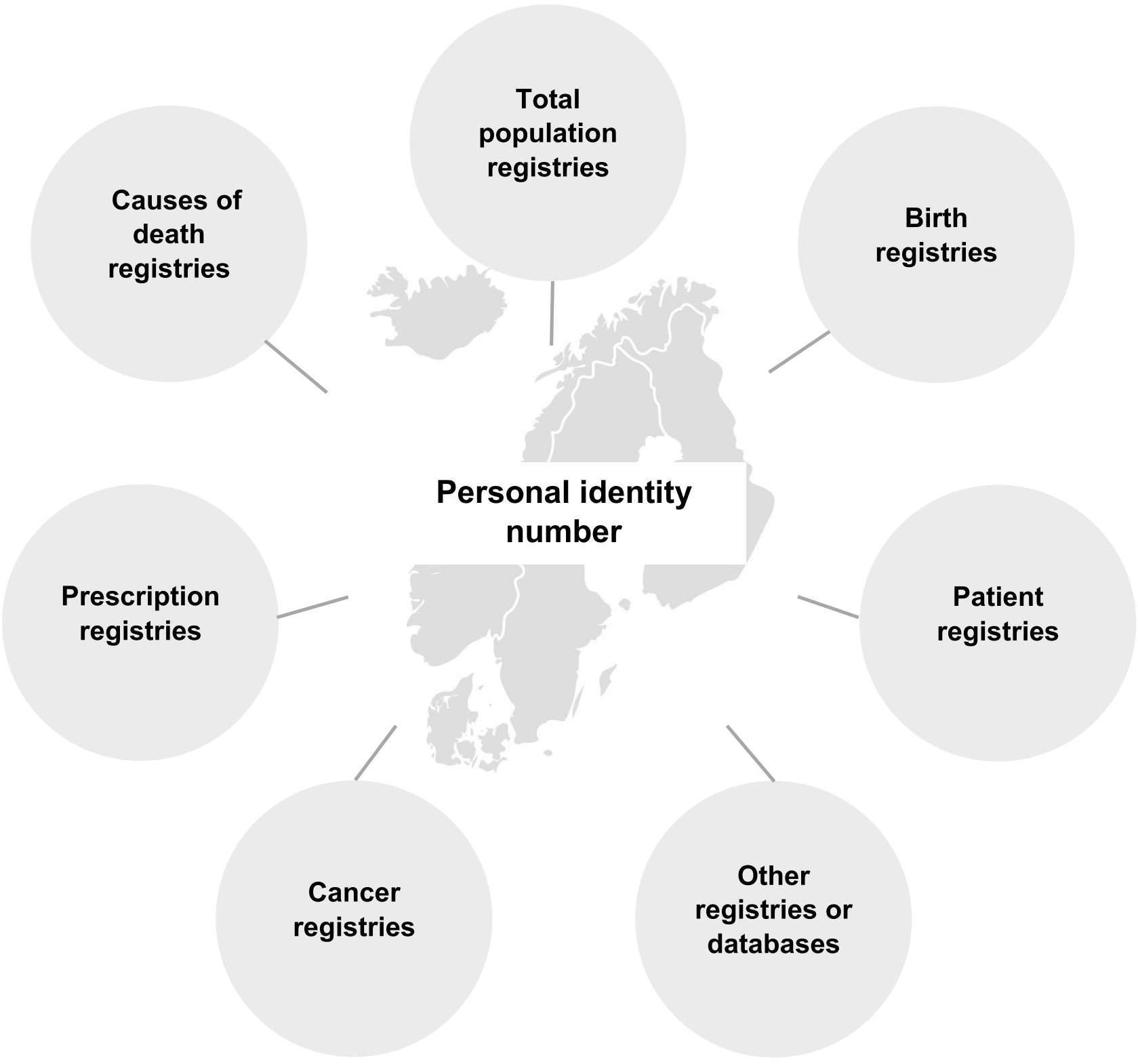

Figure 4 Combining Nordic registries by personal identity number.

Notes: Other registries and databases refer to registries containing socioeconomic data, the numerous disease or procedure registries, clinical quality databases/registries, surveys, researcher-initiated cohorts and biobanks.

\section{Population-Based Registries}

The Nordic registries provide population-based data that are routinely and prospectively collected on individuals lives and health. The registries have several advantages, but also potential disadvantages, described in overall terms below and in more detail in the subsequent sections on key registries.

\section{Advantages}

The Nordic registries are population-based with virtually complete follow-up and exact censoring information, reducing the risk of selection bias. Population-based registries share the feature of intended coverage of all members of the underlying source population with a given set of traits, exposures, or events, making selection bias less likely at study inclusion. ${ }^{50}$ The term "coverage" denotes the proportion of all health care units that report to the registry. Although the coverage of a population-based registry may be incomplete, it is the intention that defines the term, in contrast to registries that rely on, for example, insurance or survey data. Importantly, population-based studies are not necessarily 
free of selection bias. The collection of national registry data in the Nordic countries is further independent of the research question, which reduces the risk of certain types of bias (eg, recall bias). The large size of the registries provides an opportunity to study rare exposures or outcomes, increasing the precision of estimates. Furthermore, many of the registries offer the possibility for long-term follow-up. Lastly, as the data are already available in the registries, the time and cost spent on a typical registry-based study are probably less than that spent on studies using primary data collection.

\section{Potential Disadvantages}

The Nordic registries may also have potential disadvantages, mainly in the areas of data quality and data availability, and the validation of variables is important for the quality of registrybased research. The registries covered in this review are mainly administrative with the aim of health care surveillance, planning, and reimbursement. ${ }^{7}$ When using registry data for research, one should therefore bear in mind the data quality in terms of validity and completeness. Validity denotes the extent to which a variable measures the intended event, trait, or exposure and is most often described in terms of the positive predictive value. The positive predictive value denotes the probability that a person has a condition or disease given that this person is recorded with the condition or disease. The validity of health information in registries may vary extensively. The completeness refers to the percentage of all eligible patients with a diagnosis in the target population who are recorded in the registry. Thus, completeness is related to sensitivity. Lastly, registries may directly lack information because data collection is predetermined and not controlled by the researcher. Data quality and availability obviously impact potential exposure and outcome misclassification, but may also affect a researcher's ability to control for confounding.

Although the Nordic registries were established at different points in time (Figure 5), they often share a similar overall structure. The number of registries and databases in each country are substantial, with more than 200 registries and databases in Denmark alone. ${ }^{7}$ Below, we provide an overview of some of the key registries, with a focus on registries that are present in most of the countries and may be particularly useful when conducting registry-based studies. Despite the similarities within the Nordic registries, researchers should keep in mind that some differences do exist, including variable types and registration practices. In addition, the organization and structure of the health care systems affect the registration practices. Having experienced collaborators within each country is important in order to use and manage the registries correctly.

\section{Key Registries}

Below we describe the total population, birth, patient, cancer, prescription, and causes of death registries with a focus on period of coverage, selected key variables, and potential limitations. We have chosen to describe these specific registries, as they share similarities in context and structure between the countries and they are frequently used for research. In addition, each of the Nordic countries has various other registries, databases, and biobanks available for research. In the end of this section, we will briefly mention a selection of these.

\section{The Total Population Registries}

All Nordic countries maintain registries of their entire population with continuously updated information on the variables presented in Table 1. ${ }^{46,51,52}$ The coverage periods of the registries are shown in Figure 5. ${ }^{46,51,52}$

These registries are intended for administrative purposes and, for example, form the basis for monitoring of population statistics, demographics, and development. In addition, they are also widely used for research and play a key role in almost all registry-based studies. The total population registries are important tools in epidemiological research and provide inimitable possibilities. These registries hold information on date of birth and death and allow for virtually complete follow-up and exact censoring information for an entire population. The registries may further be used for sampling general population comparison cohorts (cohort studies) ${ }^{53}$ or controls (case-control studies) ${ }^{54}$ identification of family members as eg siblings, ${ }^{55}$ sampling of people for surveys, ${ }^{56}$ or subsequent long-term follow-up in clinical trials. ${ }^{57}$ Regarding case-control studies, the registries also permit risk-set sampling, so that estimated odds ratios provide unbiased estimates of incidence rate ratios, as well as back-calculation of incidence rate differences. ${ }^{54,58-}$ ${ }^{60}$ Lastly, non-response may introduce bias in studies using surveys. However, individual-level linkage of participants and non-participants to other registries using the total population registries allows the calculation of calibrated weights that can be utilized to diminish such bias in studies using survey data.61-63

\section{Birth Registries}

Each Nordic country has a nationwide birth registry with complete coverage of live and stillbirths. ${ }^{64-70}$ Abortions are not registered. The registries contain electronically 


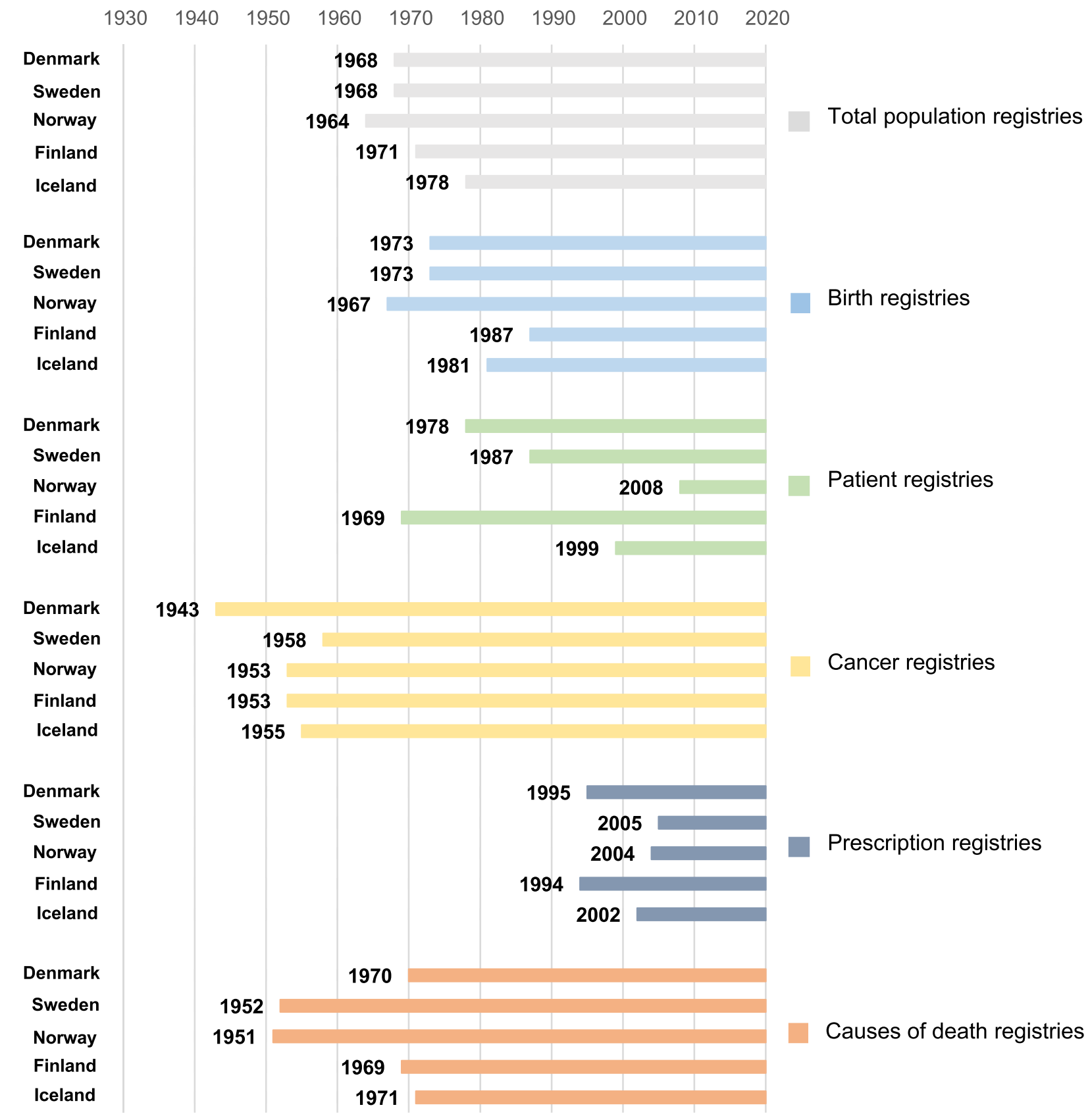

Figure 5 The time coverage of selected Nordic population-based registries.

Notes: Only the time for complete nationwide coverage is displayed. The Finnish Hospital Discharge Register has had nationwide coverage since 1967 but was limited by incomplete registration of the personal identity number in 1967-1968 and diagnoses in 1967-1970. The Icelandic Birth Registry was complete from I972 but electronically since 1981 .

submitted information on variables, such as the personal identity number of the live-born infant and parents, some infant and maternal characteristics, as well as information on the pregnancy and delivery. The Swedish and Norwegian registries further collect information on fertility treatments, their indications, and procedures. ${ }^{67,69}$ The midwife or physician overseeing the delivery collects the data at the hospital, or at home in the case of planned home delivery. The coverage periods of the birth registries are shown in Figure 5. ${ }^{65,67-70}$

The contents of the Nordic birth registries are similar, and selected key variables are given in Table 2. Date of birth, sex, and kinship can be obtained from the total population registries as well. 
Table I Key Variables in the Nordic Total Population Registries

\begin{tabular}{|l|}
\hline Variables \\
\hline Personal identity number \\
Date of birth \\
Country of birth \\
Name \\
Address, including date of address changes \\
Immigration and date \\
Emigration and date \\
Civil status, including changes in and personal identity number of \\
spouse or registered partner \\
Kinship, including personal identity number of parents, siblings, and \\
children \\
Date of death
\end{tabular}

\section{Strengths and Limitations}

An extensive validation of the Danish Medical Birth Register was performed in 2001, showing that most procedures, surgical codes, and diagnoses had high validity in terms of positive predictive values. However, some variables, such as pain relief procedures and uterine rupture, did not have high validity. ${ }^{71}$ The Medical Birth Registry of Norway has undergone validation of a few selected variables. $^{72,73}$ A validation study of the 1991 Finnish Medical Birth Registry found good or acceptable validity for many variables. ${ }^{74}$ Regarding diagnoses and procedures, check-box variables were generally more reliable than collection by specific codes. ${ }^{74}$

\section{Patient Registries}

The nationwide patient registries ${ }^{75-78}$ are administrative and contain electronically submitted information from hospitals, including information on inpatient hospital care and, often, hospital-based outpatient care. The primary aim of these registries is monitoring of hospital and health service utilization to provide a tool for health care planning. The coverage periods of the patient registries are shown in Figure 5. The Danish National Patient Registry ${ }^{75}$ was established in 1977 and reached complete nationwide coverage in 1978. From 1977 to 1994, it included only somatic inpatient care, but from 1995 onwards it included also somatic and psychiatric inpatient and outpatient care. From 1999, diagnostic examinations and treatments were included. The Swedish National Patient Register ${ }^{76}$ was founded in 1964 but attained complete nationwide coverage in 1987. Initially, only somatic inpatient care was included. Psychiatric contacts were added from 1973, day surgeries were added from 1997, and outpatient contacts were included from
Table 2 Selected Key Variables in the Nordic Birth Registries

\begin{tabular}{|c|c|}
\hline $\begin{array}{l}\text { Information } \\
\text { Type }\end{array}$ & Variables \\
\hline $\begin{array}{l}\text { Basic } \\
\text { information }\end{array}$ & $\begin{array}{l}\text { The personal identity number of the infant } \\
\text { The personal identity number of the mother } \\
\text { The personal identity number of the father }\end{array}$ \\
\hline $\begin{array}{l}\text { Delivery } \\
\text { information }\end{array}$ & $\begin{array}{l}\text { Date of birth } \\
\text { Place of birth } \\
\text { Presentation at birth (eg, cephalic, breech, or } \\
\text { shoulder presentation) } \\
\text { Method of delivery } \\
\text { Delivery complications } \\
\text { Procedures around delivery }\end{array}$ \\
\hline $\begin{array}{l}\text { Maternal } \\
\text { characteristics }\end{array}$ & $\begin{array}{l}\text { Age at birth } \\
\text { Height, weight, body mass index } \\
\text { Smoking status }^{\mathrm{b}} \\
\text { Parity } \\
\text { Diagnoses }^{\mathrm{d}} \text { and complications during pregnancy } \\
\text { or delivery }^{\text {Number of previous pregnancies and deliveries }}\end{array}$ \\
\hline $\begin{array}{l}\text { Infant } \\
\text { characteristics }\end{array}$ & $\begin{array}{l}\text { Single or multiple birth } \\
\text { Sex } \\
\text { Gestational age at birth } \\
\text { Birth weight } \\
\text { Length } \\
\text { Head circumference } \\
\text { Live or stillborn } \\
\text { Health status of the child (Apgar score, infant } \\
\text { diagnoses, and treatment) } \\
\text { Congenital malformations at birth }\end{array}$ \\
\hline
\end{tabular}

Notes: ${ }^{\mathrm{N}} \mathrm{Not}$ in Sweden and Finland but can be obtained through linkage to the total population registries. ${ }^{b}$ The coverage period of these variables varies considerably across the countries. 'Sweden also record use of snuff. ${ }^{d}$ Not recorded in the Danish Medical Birth Registry, but some diagnoses may be obtained through linkage to the Patient Registry. ${ }^{~}$ Gestational age at which stillbirth is defined varies by country and calendar year. ${ }^{\mathrm{f}}$ More detailed information may be obtained in the registries of congenital anomalies or patient registries, depending on country. The birth registries of Norway and Sweden also contain information on fertility treatment procedures and indications.

2001. The Norwegian Patient Registry ${ }^{77}$ was founded in 1997. When established, the registry covered inpatients in somatic hospitals. Psychiatric hospital data for adults were included in 2001, whereas data from children were included in 2003. In $2009 / 2010$, the registry was further expanded to include information from emergency departments. Importantly, before 2008, the registry did not include information on the personal identity number. The Finnish Hospital Discharge Register has had complete coverage since 1969 (including personal identity 
Table 3 Selected Key Variables in the Nordic Patient Registries

\begin{tabular}{|l|l|}
\hline Information Type & Variables \\
\hline The patient & $\begin{array}{l}\text { Personal identity number } \\
\text { Area of residence }\end{array}$ \\
\hline $\begin{array}{l}\text { Hospital and } \\
\text { department }\end{array}$ & Hospital code \\
Department code/specialty
\end{tabular}

Abbreviation: ICD, the International Statistical Classification of Diseases and Related Health Problems for coding diagnoses.

numbers), but was replaced in 1994 by the Finnish Care Register for Health Care. ${ }^{78}$ The Hospital Discharge Register only included data on inpatient care, whereas the Care Register for Health Care also contains data on specialized outpatient care (since 1998) and day surgery (since 1994). The Icelandic Hospital Discharge Registry ${ }^{79}$ has been nationwide since 1999. Until 2009, the registry included inpatient contacts only, but from 2010 onwards the registry also collected information on outpatient contacts.

Table 3 provides an overview of selected key variables in the Nordic patient registries.

The Nordic countries use different versions of the International Statistical Classification of Diseases and Related Health Problems (ICD) for coding diagnoses (Table 4). ${ }^{80}$

Since 1996/1997, a Nordic collaboration has defined surgical procedures in the Nordic Medico-Statistical Committee (NOMESCO), making the coding and selection of surgical procedures more homogenous between the countries. However, the NOMESCO Classification of Surgical Procedures (NCSP) has not been updated since 2011. Because the national versions have been updated with new codes, the classification cannot be used before mapping the old NCSP and its national versions.

The patient registries do not capture information from GPs, but separate registries exist with such information for Norway, ${ }^{77}$ Finland, ${ }^{81}$ Iceland, ${ }^{82}$ Denmark, ${ }^{83}$ and probably soon for Sweden. However, the level of details in these registries varies extensively.

\section{Strengths and Limitations}

The Danish, Swedish, and Norwegian patient registries have undergone extensive validation, though some work still persists, and findings indicate a high positive predictive value for many, but not all, diagnoses. ${ }^{75-77}$ Furthermore, some diagnoses in the Finnish patient registry have been validated. ${ }^{84}$ The completeness of the diagnoses (relative to the general population) are dependent on whether the condition requires hospitalization, as well as the diagnostic and coding practices. For example, completeness is high for conditions such as acute myocardial infarction or hip fractures, which require a hospital encounter, ${ }^{75,76}$ whereas completeness is low for conditions such as hypertension, type 2 diabetes, asthma, or chronic obstructive pulmonary disease (COPD), which are often diagnosed and treated by GPs (ie, outside hospitals). ${ }^{75,76}$ Under the latter circumstances, researchers may benefit from using algorithms based on, for example, prescription data to increase completeness. Information on lifestylerelated factors, such as smoking, alcohol drinking, or body mass index, is generally lacking or incompletely recorded. Clinical details, such as disease severity, are also absent. Such information may be captured in other

Table 4 Timeline for Use of the International Statistical Classification of Diseases and Related Health Problems (ICD) Coding Systems in the Patient Registries by Country

\begin{tabular}{|l|l|l|l|l|}
\hline & ICD-7 & ICD-8 & ICD-9 & ICD-I0 \\
\hline Denmark & NA & $1977-1993$ & NA & $1994-$ \\
Sweden & $1964-1967^{\mathrm{a}}$ & $1968^{\mathrm{a}}-1986$ & $1987-1996$ & $1997^{\mathrm{b}}-$ \\
Norway & NA & NA & $1997-1998$ & $1999-$ \\
Finland & NA & $1969-1986$ & $1987-1995$ & $1996-$ \\
Iceland & NA & NA & NA & $1999-$ \\
\hline
\end{tabular}

Notes: a Officially, the change to ICD-8 occurred in 1968, but in practice ICD-7 was used during 1968, and only in I969 was ICD-8 used. ${ }^{b}$ The Skåne region introduced ICD-I0 in I998. Source: Health Classifications in the Nordic Countries (2006). Björn Smedby and Gunnar Schiøler. Responsible organization: Nordic Council of Ministers, NOMESCONOSOSCO. (http://norden.diva-portal.org/smash/get/diva2:970544/FULLTEXT0I.pdf).

Abbreviation: NA, not applicable. 
Table 5 Selected Key Variables in the Nordic Cancer Registries

\begin{tabular}{|l|l|}
\hline $\begin{array}{l}\text { Information } \\
\text { Type }\end{array}$ & Variables \\
\hline The patient & $\begin{array}{l}\text { Personal identity number } \\
\text { Date of birth } \\
\text { Sex } \\
\text { Place of residence (unit) } \\
\text { Vital status } \\
\text { Date of death }\end{array}$ \\
\hline $\begin{array}{l}\text { Tumor } \\
\text { characteristics }\end{array}$ & $\begin{array}{l}\text { Date of diagnosis } \\
\text { Topography (primary site) } \\
\text { Morphology/histology } \\
\text { Tumor stage or grade } \\
\text { Method of confirmation } \\
\text { Behavior (malignant, premalignant, and } \\
\text { borderline behavior) }\end{array}$ \\
\hline
\end{tabular}

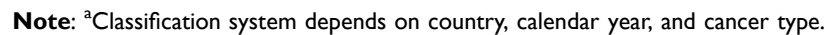

databases, such as disease or procedure registries, clinical quality databases/registries, or surveys.

\section{Cancer Registries}

All of the Nordic countries have well-established cancer registries with data on incident malignancies and a few certain benign tumors. ${ }^{85-91}$ Recurrence and subsequent metastases are not recorded. In contrast to the other registries described in this review, the cancer registries are not administrative, but were created mainly for research purposes. The cancer registries receive information from multiple sources, including hospitals, outpatient clinics, primary care physicians, pathology and cytology laboratories, and death certificates. ${ }^{85}$ The coverage periods of the cancer registries are shown in Figure $5 .^{85-91}$ The cancer registries are used to monitor cancer incidence. The cancer registries of the Nordic countries have established an association and a partnership with the International Agency for Research on Cancer (IARC). As a result, IARC has developed NORDCAN 2.0, which is an interactive and analytical tool and database enabling the comparison of cancer statistics for the Nordic countries. Information from NORDCAN 2.0 includes estimates on incident cancer cases, cancer mortality, number of persons living with a cancer diagnosis (prevalence), and cancer survival, among others. ${ }^{92}$

Table 5 provides selected key variables in the Nordic cancer registries.

The Nordic countries have used different systems to code topography and morphology (for more details please
Table 6 Selected Key Variables in the Nordic Prescription Registries

\begin{tabular}{|l|l|}
\hline $\begin{array}{l}\text { Information } \\
\text { Type }\end{array}$ & Variables \\
\hline The patient & $\begin{array}{l}\text { Personal identity number (or pseudonymized } \\
\text { number) } \\
\text { Sex } \\
\text { Date of birth }\end{array}$ \\
\hline The prescriber & $\begin{array}{l}\text { Prescriber type (eg, GP, hospital physician, or } \\
\text { private physician) }\end{array}$ \\
\hline The pharmacy & $\begin{array}{l}\text { Identifier } \\
\text { Location of the pharmacy }\end{array}$ \\
\hline The drug & $\begin{array}{l}\text { Date of dispensing } \\
\text { Nordic article number (unique identifier) } \\
\text { Anatomical Therapeutic Chemical classification } \\
\text { (ATC) code } \\
\text { Number of packages dispensed } \\
\text { Number of tablets in one package } \\
\text { Tablet strengths } \\
\text { The defined daily dose (DDD) } \\
\text { Formulation of the drug } \\
\text { Drug reimbursement }\end{array}$ \\
\hline
\end{tabular}

Note: a Location not recorded in the Finnish prescription registry but can be linked.

see Pukkala et $\mathrm{al}^{85}$ ). Today, all countries use the International Classification of Diseases for Oncology, third edition (ICD-O-3) to code morphology. Denmark also uses ICD-10 codes (recoded from ICD-8 codes in 1978-1993) and Sweden ICD-7 codes to identify cancer diagnoses.

\section{Strengths and Limitations}

Cancer reporting is mandatory in all Nordic countries, and all of the cancer registries include high quality data in terms of completeness and validity. ${ }^{85,87,88,90}$ In addition, microscopic verification of the cancers is frequent (93$98 \%$ ) in all countries. ${ }^{85}$ The validity of the cancer registries is fortified by manual quality control routines and notifications from different data sources, which also secures high completeness.

\section{Prescription Registries}

Each Nordic country has a nationwide prescription registry containing electronically submitted information on prescriptions dispensed by pharmacies. ${ }^{93-98}$ The registries are valuable data sources for drug utilization studies or pharmacoepidemiological research on the effectiveness or 
safety of medical drugs. The coverage periods of the prescription registries are shown in Figure $5 .{ }^{93-98}$

Table 6 shows selected key variables in the Nordic prescription registries.

The Swedish, Norwegian, Finnish, and Icelandic registries contain information on prescribed daily dose, but only as free text, which renders the information difficult to utilize in research. The Danish registry does not capture information on prescription duration, but in many pharmacoepidemiological studies, prescription duration or the definition of treatment episodes are important information. For some medications, clinical input may be used to guide the duration of individual prescriptions (eg, assuming use of one defined daily dose or one tablet per day), or datadriven methods may be utilized, such as the parametric or reverse waiting time distribution. ${ }^{99-102}$

Currently, all registries contain information on both reimbursed and non-reimbursed medications. However, until 2017, the Finnish registry recorded information only on reimbursed medications. ${ }^{93}$ Individual-level data on drug use in hospitals are not available in the prescription registries. Some medications, such as chemotherapeutics or immunotherapies, are typically registered in the patient registries by treatment or sometimes ATC codes. Individual-level information on drug use in nursing homes is available in Denmark, Sweden, and Iceland (in Iceland from 2007 onwards). ${ }^{93}$ Furthermore, the majority of over-the-counter (OTC) medicines, such as non-steroidal anti-inflammatory drugs or paracetamol, are not captured except when prescribed to patients, typically in patients with chronic diseases for whom reimbursement is needed.

In addition to existing individual-level information, aggregated drug sale information is public and freely available in Denmark (www.medstat.dk) ${ }^{103}$ Finland (www.fimea.fi/web/en/databases_and_registers/consump tion-information) ${ }^{104}$ Sweden (https://sdb.socialstyrelsen. se/if lak/val.aspx) ${ }^{105}$ and Norway (www.norpd.no). ${ }^{106}$ In Denmark and Finland, aggregate statistics are available for community pharmacy-dispensed medication, drug use in hospitals, and OTC medicines, whereas Norwegian and Swedish statistics only provide information on community pharmacy-dispensed medication.

\section{Strengths and Limitations}

Completeness for drugs dispensed at community pharmacies and the validity of medication records is considered high because of legislation and other incentives (eg, financial) that motivate pharmacies to collect and send the data electronically to the registries. ${ }^{93-95,97}$ Nevertheless, several limitations need to be considered. The lack of information on inhospital drug use may create observation gaps or an unmeasurable exposure time during hospital stays. In addition, secondary non-adherence, defined as filling a prescription but not taking the drug, cannot be ruled out. However, primary non-adherence, defined as not filling a prescription, is not an issue, as the registries only have information on dispensed drugs. Many of the prescription registries lack information on treatment indication and the severity of the conditions being treated. Absence of this information makes it even more difficult to control for confounding by indication or disease severity. Several approaches can diminish confounding by indication or disease severity, including the new use active-comparator design ${ }^{107}$ or the inclusion of proxies for disease severity, such as number of hospital contacts or prescriber type (GP vs hospital physician). Since 2004, The Danish National Prescription Registry has recorded a numerical code for the treatment indication. Physicians should always state the treatment indication on prescriptions, but some do so in free text, which is then not reported to the registry. In Norway, reimbursement codes may be used (ICD10 or ICPC-2).

Table 7 Selected Key Variables in the Nordic Causes of Death Registries

\begin{tabular}{|l|l|}
\hline Information Type & Variables \\
\hline The person & $\begin{array}{l}\text { Personal identity number } \\
\text { Place of residence }\end{array}$ \\
\hline The death & $\begin{array}{l}\text { Date of death (or date of discovery if } \\
\text { found dead) } \\
\text { Manner of death (natural, accident, } \\
\text { violence, suicide, uncertain) } \\
\text { Underlying cause of death } \\
\text { The immediate or direct cause of death } \\
\text { The contributing causes of death } \\
\text { Place of death } \\
\text { (private residence, nursing home, } \\
\text { hospital) } \\
\text { Autopsy performed (yes/no) } \\
\text { Type of autopsy (clinical, medico-legal) }\end{array}$ \\
\hline Physician issuing the & $\begin{array}{l}\text { Hospital physician, GP, health officer, etc } \\
\text { death certificate }\end{array}$ \\
\hline
\end{tabular}

Notes: ${ }^{a}$ The Swedish Causes of Death Registry does not record immediate/direct cause of death directly. Nevertheless, this information can mostly be obtained by the position of the cause of death on the death certificate (the first line on the death certificate corresponds to the immediate/direct cause of death). 


\section{Causes of Death Registries}

All Nordic countries have a long tradition of recording cause of death data, which are stored in nationwide administrative registries. These registries are used to estimate and inform on cause-specific mortality statistics. The coverage periods of the registries are shown in Figure 5. ${ }^{108-111}$ Denmark holds the records of Danish citizens who died in Denmark, Greenland, or the Faroe Islands, whereas Finland, Sweden, and Norway also record whether citizens died abroad.

Table 7 shows selected key variables in the Nordic causes of death registries. Information on date of death can be obtained from the total population registries as well.

Causes of death are recorded using ICD codes (Supplementary Table 3) $\cdot{ }^{80}$ In general, the death registries contain information on underlying (the World Health Organization definition), immediate, and contributing causes of death.

\section{Strengths and Limitations}

The quality of the causes of death registries is affected by several factors, including the quality with which the responsible physician certifies the death, autopsy rates (which are generally low and declining), and the processing of death certificates by responsible agencies. The completeness of the causes of death registries is considered high, but validity may vary and depend on age at death (less valid in elderly) and cause of death (eg, high validity for cancers but low validity for COPD). ${ }^{108,109}$ Furthermore, the recording procedures may vary between the Nordic countries and may have also changed within each country over the years. Changes in recording procedures, shifts in the coding systems, new diagnostic techniques, the decline in autopsy rates, and altered priorities in the health care systems may all impact the reporting of causespecific mortality. Therefore, cause-specific mortality trends over the years and between-country variations need to be interpreted carefully. Information on all-cause mortality is usually retrieved from the total population registries, and this information is regarded as precise and valid. For example, $93 \%$ of all deaths are recorded in the Swedish Total Population Register within 10 days, and the remaining $7 \%$ within 30 days. ${ }^{51}$

\section{Other Registries and Databases}

The Nordic countries have a great number of other registries, databases, surveys, and biobanks available for research. ${ }^{7112-117}$ Among these are registries containing socioeconomic data on educational level and achievements, income, labor market affiliation, housing, and social benefits. ${ }^{116-123}$ Further, numerous disease and procedure registries ${ }^{7,112,113,116,117,124}$ and clinical quality databases/registries ${ }^{7,125,126}$ collect detailed clinical information on factors such as the disease of interest, disease severity and progression, drug treatment, diagnostic or treatment procedures, lifestyle factors, laboratory values, and other clinical characteristics relevant for the specific database. National or regional surveys may also contain valuable data, such as self-reported physical and mental health, social relations, lifestyle and other factors not recorded in the registries. ${ }^{7,113,117,127-130}$ Lastly, researcher-initiated cohorts $^{7,117,128,131-139}$ or biobanks ${ }^{7,128,131-145}$ are widely available.

\section{Concluding Remarks}

The unique personal identity number, assigned to all residents upon birth or immigration, makes the Nordic population a cohort that is followed its entire lifespan with exact date of death or censoring information. The wide range of populationbased registries and databases as well as surveys and biobanks make the Nordic countries a goldmine for joint health registrybased research. The similarities between and within the Nordic registries allow researchers to combine data from several countries, providing opportunities for research in large study populations with long and complete follow-up. Data quality as well as potential dissimilarities in registration practice, variables, and underlying health care systems between the countries should be taken into account.

\section{Examples of Nordic Health Registry-Based Research}

Nordic research collaborations have contributed with important surveillance and clinical research. For example, cancer incidence, ${ }^{146,147}$ survival, ${ }^{147-151}$ prediction, ${ }^{152}$ and risk factors ${ }^{153}$ have been described and studied extensively using the Nordic registries. Findings of country-specific variations in eg cancer survival have already led to national improvement strategies and may also foster common surveillance and treatment guidelines in the future. ${ }^{147}$ Examples of other findings include studies by Stephanson et $\mathrm{al}^{1}$ and Kieler et $\mathrm{al}^{2}$ (cohort studies of 1.6 million infants), which found no association between the use of selective serotonin reuptake inhibitors (SSRIs) during pregnancy and the risk of stillbirth, neonatal mortality, or post-neonatal mortality; however, an association with neonatal persistent pulmonary hypertension 
Table 8 Country-Specific Overview of Permission Needed for Registry-Based Research and Where to Apply for Data

\begin{tabular}{|c|c|c|}
\hline & Required Permissions & Where to Apply for Data \\
\hline Denmark & $\begin{array}{l}\text { Approval from the Danish Data Protection Agency; from a practical perspective this is } \\
\text { done by reporting the study to local authorities with data responsibility (universities or } \\
\text { regions) } \\
\text { No ethical permission is needed }\end{array}$ & $\begin{array}{l}\text { The Danish Health and Medicines } \\
\text { Authority } \\
\text { (www.sundhedsdatastyrelsen.dk) } \\
\text { Statistics Denmark } \\
\text { (www.dst.dk) }\end{array}$ \\
\hline Sweden & $\begin{array}{l}\text { Approval from the relevant governmental registry holder (Statistics Sweden and the } \\
\text { National Board of Health and Welfare) } \\
\text { Ethical permission is required from the Ethical Review Authority. }\end{array}$ & $\begin{array}{l}\text { The National Board of Health and } \\
\text { Welfare (www.socialstyrelsen.se) } \\
\text { Statistics Sweden (www.scb.se) }\end{array}$ \\
\hline Norway & Ethical permission is required from the regional ethical committee & $\begin{array}{l}\text { Helsedata (www.helsedata.no) } \\
\text { Statistics Norway (www.ssb.no) }\end{array}$ \\
\hline Finland & $\begin{array}{l}\text { Approval from the Health and Social Data Permit Authority (Findata) and/or Statistics } \\
\text { Finland } \\
\text { No ethical permission is needed }\end{array}$ & $\begin{array}{c}\text { Findata (www.findata.fi) } \\
\text { Statistics Finland (www.stat.fi) }\end{array}$ \\
\hline Iceland & $\begin{array}{l}\text { Approval from the National Bioethics Committee (including a review from the National } \\
\text { Data Protection Agency) } \\
\text { Approval from the relevant governmental registry holder }\end{array}$ & $\begin{array}{l}\text { The Directorate of Health (www.landlae } \\
\qquad \begin{array}{l}\text { knir.is) } \\
\text { Statistics Iceland (www.statice.is) }\end{array}\end{array}$ \\
\hline
\end{tabular}

was found with SSRI use in late pregnancy (adjusted odds ratio of 2.1 and absolute risk of 3 per 1000 vs 1.2 per 1000 in the background population). A study by Bateman et $\mathrm{al}^{3}$ (cohort study of $\sim 18,500$ hypertensive pregnancies) found that maternal use of $\beta$-blockers in the first trimester of pregnancy was not associated with a large increase in the overall risk of malformations (adjusted relative risk 1.07, risk difference of 3.0 per 1000 infants) or the risk of cardiac malformations (adjusted relative risk 1.12, risk difference of 2.1 per 1000). A study by Daltveit et al ${ }^{4}$ (case-control study including 62,295 cancer cases and 724,542 controls) reported an increased risk of cancer in individuals with birth defects. The odds ratio for cancer was 1.54 for individuals with nonchromosomal birth defects and 5.53 for those with chromosomal anomalies. ${ }^{4}$ Two studies by Olén et $\mathrm{al}^{5,6}$ (cohort studies of 1 million and 500,000 individuals, respectively) assessed the risk of colorectal cancer and mortality from colorectal cancer in patients with ulcerative colitis $(n=100,000)$ and Crohn's disease $(n=47,000)$ during modern treatment and surveillance paradigms compared to the general population. Patients with ulcerative colitis or Crohn's disease were at increased risk of colorectal cancer and increased risk of dying from the cancer. These excess risks declined substantially over time (1969-2017), but surveillance programs may still have room for improvement. ${ }^{5,6}$ Lastly, the SCAN-AED (Nordic register-based study of antiepileptic drugs in pregnancy) is a project that aims to investigate the association between in utero exposure to antiepileptic drugs and folic acid supplements, and later disease in the mother and child. ${ }^{154}$

\section{Practical and Ethical Aspects}

Combining Nordic registries can be challenging from both the practical and legal perspective. ${ }^{155}$ Currently, organizations exist to facilitate Nordic collaboration research, including NordForsk. NordForsk was established in 2005 under the Nordic Council of Ministers and facilitates and funds Nordic research and infrastructure. ${ }^{156}$ Different initiatives have also been created to ease cross-border data-sharing and transfer, including current and future platforms, such as NordMAN and Nordic Commons. ${ }^{157,158}$ Yet, legal and practical aspects can still hamper the process. The NORDCAN collaboration has been successful in pooling and harmonizing data. ${ }^{92}$

\section{Practical Aspects}

To initiate joint Nordic research, the first step is to establish collaboration between experienced researchers within each country. The next step is to write a detailed protocol and analysis plan with a clear aim and description of the required variables. Variables are not always present in all country-specific registries and coding practices may also vary. In addition, permissions need to be obtained within each country. The timeline is often extensive for obtaining permission and retrieving data. An additional major barrier 
is that Danish data cannot legally be transferred out of the country, and other countries need to provide their data to Statistics Denmark or the Danish Health and Medicines Authority. Other Nordic countries are increasingly moving towards specific remote access environments for secure data processing. Whether Nordic data can be gathered in such environments and on which principles is still unclear.

\section{Ethical Aspects and Data Permissions}

Researchers must obtain permission in each country. Necessary permissions and procedures vary between the Nordic countries ${ }^{155,159}$ (for a detailed review see Ludvigsson et $\mathrm{al}^{159}$ ). Table 8 provides a country-specific overview of the permissions needed for registry-based research and information on where to apply for the data. A shared feature of legislation in all Nordic countries is that no informed patient consent is required for collection of large-scale data in the national registries reviewed in this paper.

\section{Data Transfer Out of the Country}

Currently, all data except Danish data may (theoretically) be transferred out of country. If Danish data are needed, two solutions may exist depending on the analytic strategy of the study. If an individual-level analytical approach is wanted, data from the other Nordic countries may be transferred to and stored at Danish servers. However, a legal barrier to this is the requirement that only (one) Danish researcher can be responsible for the data (ie data controller). This means that other countries must resign data responsibility, which can hamper or even stop the data transfer process. Another option is to choose a meta-analytic approach, storing and analyzing the data in their respective countries and combining the results in a pooled analysis.

In general, the data themselves are free of charge, but administrative handling and data processing are not. If the data are to be analyzed in a remote server, additional fees apply.

\section{Future Directions}

Joint Nordic data resources remain underutilized in health research, mainly due to legal and practical difficulties in cross-border sharing of data. To fully exploit Nordic joint research, these barriers must be overcome. Future tasks include clear and transparent legal pathways and a framework to ease practical aspects of data transfer and storage. Such tasks, likely, require a collaborative effort between the political administrative levels, organizations with interest in joint research as well as register owners and data processors.

\section{Ethical Approval}

Not needed.

\section{Funding}

There is no funding to report.

\section{Disclosure}

Dr Ludvigsson coordinates a study on behalf of the Swedish IBD quality register (SWIBREG). This study has received funding from Janssen corporation. The Department of Clinical Epidemiology, Aarhus University Hospital, receives funding for other studies from companies in the form of research grants to (and administered by) Aarhus University. None of these studies have any relation to the present study. All authors declare no conflicts of interest.

\section{References}

1. Stephansson O, Kieler H, Haglund B, et al. Selective serotonin reuptake inhibitors during pregnancy and risk of stillbirth and infant mortality. JAMA. 2013;309(1):48-54. doi:10.1001/ jama.2012.153812

2. Kieler H, Artama M, Engeland A, et al. Selective serotonin reuptake inhibitors during pregnancy and risk of persistent pulmonary hypertension in the newborn: population based cohort study from the five Nordic countries. BMJ. 2012;344:d8012.

3. Bateman BT, Heide-Jørgensen U, Einarsdóttir K, et al. $\beta$-blocker use in pregnancy and the risk for congenital malformations: an international cohort study. Ann Intern Med. 2018;169(10):665673.

4. Daltveit DS, Klungsøyr K, Engeland A, et al. Cancer risk in individuals with major birth defects: large Nordic population based case-control study among children, adolescents, and adults. BMJ. 2020;371:m4060.

5. Olén O, Erichsen R, Sachs MC, et al. Colorectal cancer in ulcerative colitis: a Scandinavian population-based cohort study. Lancet. 2020;395(10218):123-131.

6. Olén O, Erichsen R, Sachs MC, et al. Colorectal cancer in Crohn's disease: a Scandinavian population-based cohort study. lancet Gastroenterol Hepatol. 2020;5(5):475-484.

7. Schmidt M, Schmidt SAJ, Adelborg K, et al. The Danish health care system and epidemiological research: from health care contacts to database records. Clin Epidemiol. 2019;11:563-591.

8. Statistics Norway. Spesialisthelsetjenesten. Available from: https:// www.ssb.no/statbank/table/06922/. Accessed February 24, 2021.

9. Statista. Number of hospital beds in Sweden from 2000 to 2018. Available from: https://www.statista.com/statistics/557358/hospi tal-beds-in-sweden/. Accessed March 04, 2021.

10. HealthManagement.org. Overview of the Healthcare Systems in the Nordic Countries Available from: https://healthmanagement. org/c/cardio/issuearticle/overview-of-the-healthcare-systems-inthe-nordic-countries. Accessed May 05, 2021.

11. Anell A, Glenngård AH, Merkur S. Sweden health system review. Health Syst Transit. 2012;14(5):1-159. 
12. Sperre Saunes IKM, Sagan A. Norway: Health System Review. Health Systems in Transition. 2020.

13. Keskimäki ITL, Reissell E, Koivusalo M, et al. Finland: Health System Review. Health Systems in Transition. 2019.

14. Sigurgeirsdóttir SWJ, Maresso A. Iceland: health system review. Health Syst Transit. 2014;6(16):1-182.

15. The World Bank. Population, total - Sweden, Denmark, Finland, Iceland, Norway. Available from: https://data.worldbank.org/indica tor/SP.POP.TOTL?locations=SE-DK-FI-IS-NO. Accessed December 20, 2020.

16. The World Bank. Fertility rate, total (births per woman) - Sweden, Iceland, Norway, Denmark, Finland. Available from: https://data worldbank.org/indicator/SP.DYN.TFRT.IN?locations=SE-IS-NODK-FI. Accessed December 20, 2020.

17. The World Bank. Life expectancy at birth, female (years). Available from: https://data.worldbank.org/indicator/SP.DYN.LE00.FE.IN? end $=2018 \&$ start $=1960$. Accessed November 20, 2020 .

18. The World Bank. Life expectancy at birth, male (years). Available from: https://data.worldbank.org/indicator/SP.DYN.LE00.MA. IN?end $=2018 \&$ start=1960. Accessed December 20, 2020.

19. OECD. Health spending (indicator). Available from: https://data. oecd.org/healthres/health-spending.htm. Accessed December 20, 2020.

20. OECD. Hospital beds (indicator). Available from: https://data.oecd. org/healtheqt/hospital-beds.htm. Accessed December 20, 2020.

21. Danske Regioner. Fakta om praksis sektoren. 2018; Available from: https://www.regioner.dk/media/9205/publikation-fakta-ompraksissektoren.pdf. Accessed December 23, 2020.

22. Wettergren B, Blennow M, Hjern A, Söder O, Ludvigsson JF. Child Health Systems in Sweden. J Pediatr. 2016;177s:S187-s202.

23. 1177 Vårdguiden. Available from: https://www.1177.se/ Orebrolan/sa-fungerar-varden/varden-i-orebro-lan/egen-vardbe garan/. Accessed February 10, 2021

24. Westerlund T, Marklund B. Community pharmacy and primary health care in Sweden - at a crossroads. Pharm Pract (Granada). 2020;18(2): 1927.

25. Health Care in Figures. Available from: https://vardenisiffror.se/. Accessed January 12, 2021.

26. Ludvigsson JF. The first eight months of Sweden's COVID-19 strategy and the key actions and actors that were involved. Acta Paediatrica. 2020.

27. OECD/European Observatory on Health Systems and Policies. Sweden: Country Health Profile 2017, State of Health in the EU, OECD Publishing. Brussels: Paris/European Observatory on Health Systems and Policies; 2017.

28. Gaardsrud PØ. Styringsdata for fastlegeordningen. kvartal. 2019;4:2019.

29. Statistics Norway. GPs and emergency primary health care. Available from: https://www.ssb.no/en/helse/statistikker/fastle getj. Accessed December 12, 2020.

30. Ringard ÅSA, Sperre Saunes I, Lindahl AK. Norway: health system review. Health Systems in Transition. Health Syst Transit. 2013;15(8):1-162.

31. Kaisa Möllär TP, Saukkonen S-M. Outpatient Visits to Primary and Oral Health Care 2019: 22.8 Million Visits to Health Centres. 2020.

32. The Icelandic Ministry of Health. Health Policy. A Policy for Iceland's Health Services Until 2030; 2019.

33. Sjúkratryggingar Íslands. Health Insurance in Iceland. Available at: https://www.sjukra.is/english/social-insurance-in-iceland/pay ment-participation-system/. Accessed April 12, 2021.

34. Sigríður Haralds Elínardóttir. Director of Health Statistics, Directorade of Health, Iceland.

35. The World Bank. Population ages 65 and above (\% of total population) - Denmark. Available from: https://data.worldbank. org/indicator/SP.POP.65UP.TO.ZS?locations=DK. Accessed November 23, 2020.
36. The World Bank. Population ages 65 and above (\% of total population) - Sweden. Available from: https://data.worldbank. org/indicator/SP.POP.65UP.TO.ZS?locations=SE. Accessed November 23, 2020.

37. The World Bank. Population ages 65 and above (\% of total population) - Norway. Available from: https://data.worldbank. org/indicator/SP.POP.65UP.TO.ZS?locations $=$ NO. Accessed November 23, 2020.

38. The World Bank. Population ages 65 and above (\% of total population) - Finland. Available from: https://data.worldbank. org/indicator/SP.POP.65UP.TO.ZS?locations=FI. Accessed November 23, 2020.

39. The World Bank. Population ages 65 and above ( $\%$ of total population) - Iceland. Available from: https://data.worldbank. org/indicator/SP.POP.65UP.TO.ZS?locations=IS. Accessed November 23, 2020.

40. Global burden of 369 diseases and injuries in 204 countries and territories, 1990-2019: a systematic analysis for the Global Burden of Disease Study 2019. Lancet. 2020;396(10258):1204-1222.

41. Lebano A, Hamed S, Bradby H, et al. Migrants' and refugees' health status and healthcare in Europe: a scoping literature review. BMC Public Health. 2020;20(1):1039.

42. Thordardottir EB, Yin L, Hauksdottir A, et al. Mortality and major disease risk among migrants of the 1991-2001 Balkan wars to Sweden: a register-based cohort study. PLoS Med. 2020;17(12):e1003392.

43. SSI. Salget af biologiske lægemidler til gigtsygdomme, psoriasis og tarmbetændelse stiger fortsat. 2013; Available from: file://C:/ Users/au193513/Downloads/Salget_af_biologiske_laegemidler_ til autoimmune sygdomme.pdf. Accessed March 17, 2021.

44. OECD. Hospital beds (indicator). 2020; Available from: https://data. oecd.org/healtheqt/hospital-beds.htm. Accessed November 23, 2020.

45. OECD. Health spending (indicator). 2020; Available from: https://data.oecd.org/healthres/health-spending.htm. Accessed November 23, 2020.

46. Schmidt M, Pedersen L, Sorensen HT. The Danish Civil Registration System as a tool in epidemiology. Eur J Epidemiol. 2014;29(8):541-549.

47. Ludvigsson JF, Otterblad-Olausson P, Pettersson BU, Ekbom A. The Swedish personal identity number: possibilities and pitfalls in healthcare and medical research. Eur J Epidemiol. 2009;24 (11):659-667.

48. The Norwegian Tax Administration. Norwegian identification number. Available from: https://www.skatteetaten.no/en/person/ foreign/norwegian-identification-number/what-is-an-identifica tion-number/. Accessed October 10, 2020.

49. Eiríksdóttir E How long have ID numbers been used in Iceland and why do we need them? 2012; Available from: https://www. visindavefur.is/svar.php?id=19500. Accessed February 12, 2021.

50. Olsen J, Basso O, Sørensen HT. What is a population-based registry? Scand J Public Health. 1999;27(1):78.

51. Ludvigsson JF, Almqvist C, Bonamy AK, et al. Registers of the Swedish total population and their use in medical research. Eur $J$ Epidemiol. 2016;31(2):125-136.

52. Helsedata. Population. Available from: https://helsedata.no/no/for valtere/statistisk-sentralbyra-ssb/befolkning/. Accessed October $17,2020$.

53. Adelborg K, Szépligeti SK, Holland-Bill L, et al. Migraine and risk of cardiovascular diseases: danish population based matched cohort study. BMJ. 2018;360:k96.

54. Johannesdottir SA, Horvath-Puho E, Dekkers OM, et al. Use of glucocorticoids and risk of venous thromboembolism: a nationwide population-based case-control study. JAMA Intern Med. 2013;173(9):743-752.

55. Krogh C, Fischer TK, Skotte L, et al. Familial aggregation and heritability of pyloric stenosis. JAMA. 2010;303(23):2393-2399. 
56. Larsen FB, Ankersen PV, Poulsen S. Hvordan Har Du Det? 2010 - Sundhedsprofil for Region Og Kommuner [How are You? 2010Health Profile for Region and Municipalities]. Report. Region Midtjylland, Denmark;2011.

57. Nielsen PH, Maeng M, Busk M, et al. Primary angioplasty versus fibrinolysis in acute myocardial infarction: long-term follow-up in the Danish acute myocardial infarction 2 trial. Circulation. 2010;121(13):1484-1491.

58. Vandenbroucke JP, Pearce N. Case-control studies: basic concepts. Int J Epidemiol. 2012;41(5):1480-1489.

59. Greenland S. Estimation of exposure-specific rates from sparse case-control data. J Chronic Dis. 1987;40(12):1087-1094.

60. Laugesen K, Farkas DK, Vestergaard M, Jørgensen JOL, Petersen I, Sørensen HT. Glucocorticoid use and risk of suicide: a Danish population-based case-control study. World Psychiatry. 2021;20 (1):142-143.

61. Fangel S, Linde PC, Thorsted BL. Nye Problemer Med Reprasentativitet I Surveys, Som Opregning Med Registre Kan Reducere. Metode \& Data. 2007.

62. Laugesen K, Petersen I, Pedersen L, Breinholt Larsen F, Jorgensen JOL, Sorensen HTT. Prevalence of lifestyle characteristics in glucocorticoid users and non-users: a Danish populationbased cross-sectional study. BMJ Open. 2019;9(10):e030780.

63. Laugesen K, Baggesen LM, Schmidt SAJ, et al. Social isolation and all-cause mortality: a population-based cohort study in Denmark. Sci Rep. 2018;8(1):4731.

64. Langhoff-Roos J, Krebs L, Klungsøyr K, et al. The Nordic medical birth registers-a potential goldmine for clinical research. Acta Obstet Gynecol Scand. 2014;93(2):132-137.

65. Bliddal M, Broe A, Pottegard A, Olsen J, Langhoff-Roos J. The Danish Medical Birth Register. Eur J Epidemiol. 2018;33(1):27-36.

66. Cnattingius S, Ericson A, Gunnarskog J, Källén B. A quality study of a medical birth registry. Scand J Soc Med. 1990;18 (2):143-148

67. Socialstyrelsen. The Swedish Medical Birth Registry. 2019; Available from: https://www.socialstyrelsen.se/en/statistics-anddata/registers/register-information/the-swedish-medical-birth-reg ister/. Accessed October 2, 2020.

68. Finnish Institute of Health and Welfare. Medical Birth Register. 2019; Available from: https://hl.fi/en/web/thlfi-en/statistics/infor mation-on-statistics/register-descriptions/newborns\#Name\%20of \%20the\%20register. Accessed October 6, 2020.

69. Irgens LM. The Medical Birth Registry of Norway. Epidemiological research and surveillance throughout 30 years. Acta Obstet Gynecol Scand. 2000;79(6):435-439.

70. Directorate of Health. Birth Register. Available from: https:// www.landlaeknir.is/tolfraedi-og-rannsoknir/gagnasofn/gagnasafn/ item12340/Faedingaskra-(Birth-Register. Accessed October 18, 2021.

71. Sundhedsstyrelsen C. Validering Af Landspatientregisteret (LPR) Med Henblik $\mathrm{Pa}^{\circ}$ Obstetrisk Forskning Og Kvalitetssikring-et Kvalitetsudviklingsprojekt [The Danish Health Authorities, Center for Evaluation and Medical Technology Assessment. Validation of the Danish National Patient Registry for the Purpose of Obstetric Research and Quality Assessment]. 2001.

72. Baghestan E, Børdahl PE, Rasmussen SA, Sande AK, Lyslo I, Solvang I. A validation of the diagnosis of obstetric sphincter tears in two Norwegian databases, the Medical Birth Registry and the Patient Administration System. Acta Obstet Gynecol Scand. 2007;86(2):205-209.

73. Engeland A, Bjørge T, Daltveit AK, Vollset SE, Furu K. Validation of disease registration in pregnant women in the Medical Birth Registry of Norway. Acta Obstet Gynecol Scand. 2009;88(10):1083-1089.
74. Gissler M, Teperi J, Hemminki E, Meriläinen J. Data quality after restructuring a national medical registry. Scand J Soc Med. 1995;23(1):75-80.

75. Schmidt M, Schmidt SA, Sandegaard JL, Ehrenstein V, Pedersen L, Sorensen HT. The Danish National Patient Registry: a review of content, data quality, and research potential. Clin Epidemiol. 2015;7:449-490.

76. Ludvigsson JF, Andersson E, Ekbom A, et al. External review and validation of the Swedish national inpatient register. BMC Public Health. 2011;11:450.

77. Bakken IJ, Ariansen AMS, Knudsen GP, Johansen KI, Vollset SE. The Norwegian Patient Registry and the Norwegian Registry for Primary Health Care: research potential of two nationwide healthcare registries. Scand J Public Health. 2020;48(1):49-55.

78. Finnish Institute for Health and Welfare. Care Register for Health Care. 2016; Available from: https://thl.fi/en/web/thlfi-en/statistics/ information-on-statistics/register-descriptions/care-register-forhealth-care\#data. Accessed June 10, 2020.

79. Directorate of health. Hospital Discharge Register. Available from: https:/www.landlaeknir.is/tolfraedi-og-rannsoknir/gagna sofn/gagnasafn/item12464/Vistunarskra-heilbrigdisstofnana. Accessed June 16, 2021. Accessed October 19, 2020.

80. Smedby BSG. Health Classifications in the Nordic Countries. 2006.

81. Finnish Institute for Health and Welfare. Register of Primary Health Care visits. 2015; Available from: https://thl.fi/en/web/thlfi-en/statis tics/information-on-statistics/register-descriptions/register-of-pri mary-health-care-visits. Accessed June 16, 2021. 6, 2020.

82. Directorate of Health. Register of Primary Health Care Contacts. Available from: https:/www.landlaeknir.is/tolfraedi-og-rannso knir/gagnasofn/gagnasafn/item 12460/Samskiptaskra-heilsugae slustodva-(Register-of-Primary-Health-Care-Contacts). Accessed June 16, 2021. Accessed October 19, 2020.

83. Andersen JS, Olivarius Nde F, Krasnik A. The Danish National Health Service Register. Scand J Public Health. 2011;39(7 Suppl):34-37.

84. Sund R. Quality of the Finnish Hospital Discharge Register: a systematic review. Scand J Public Health. 2012;40(6):505515.

85. Pukkala E, Engholm G, Højsgaard schmidt LK, et al. Nordic Cancer Registries - an overview of their procedures and data comparability. Acta Oncologica (Stockholm, Sweden). 2018;57 (4):440-455.

86. Gjerstorff ML. The Danish Cancer Registry. Scand J Public Health. 2011;39(7 Suppl):42-45.

87. Barlow L, Westergren K, Holmberg L, Talbäck M. The completeness of the Swedish Cancer Register: a sample survey for year 1998. Acta Oncologica (Stockholm, Sweden). 2009;48 (1):27-33.

88. Larsen IK, Småstuen M, Johannesen TB, et al. Data quality at the Cancer Registry of Norway: an overview of comparability, completeness, validity and timeliness. Eur J Cancer. 2009;45 (7):1218-1231.

89. Bakken IJ, Gystad SO, Christensen ØO, et al. Comparison of data from the Norwegian Patient Register and the Cancer Registry of Norway. Tidsskrift for Den Norske Laegeforening: Tidsskrift for Praktisk Medicin, Ny Raekke. 2012;132(11):1336-1340.

90. Leinonen MK, Miettinen J, Heikkinen S, Pitkäniemi J, Malila N. Quality measures of the population-based Finnish Cancer Registry indicate sound data quality for solid malignant tumours. Eur J Cancer. 2017;77:31-39.

91. Sigurdardottir LG, Jonasson JG, Stefansdottir S, et al. Data quality at the Icelandic Cancer Registry: comparability, validity, timeliness and completeness. Acta Oncologica (Stockholm, Sweden). 2012;51(7):880-889. 
92. International Agency for Research on Cancer. NORDCAN. Available from: https://nordcan.iarc.fr/en. Accessed May 6, 2021.

93. Furu K, Wettermark B, Andersen M, Martikainen JE, Almarsdottir AB, Sørensen HT. The Nordic countries as a cohort for pharmacoepidemiological research. Basic Clin Pharmacol Toxicol. 2010;106(2):86-94.

94. Pottegard A, Schmidt SA, Wallach-Kildemoes H, Sorensen HT, Hallas J, Schmidt M. Data Resource Profile: the Danish National Prescription Registry. Int J Epidemiol. 2016.

95. Wettermark B, Hammar N, Fored CM, et al. The new Swedish Prescribed Drug Register-opportunities for pharmacoepidemiological research and experience from the first six months. Pharmacoepidemiol Drug Saf. 2007;16(7):726-735.

96. Helsedata. Reseptregisteret. Available from: https://helsedata.no/ no/forvaltere/folkehelseinstituttet/reseptbasert-legemiddelregister/ . Accessed October 20, 2020.

97. Furu K. Establishment of the nationwide Norwegian Prescription Database (NorPD) - new opportunities for research in pharmacoepidemiology in Norway. Norsk Epidemiologi. 2009;18:2.

98. Directorate of Health. Prescription Medicines Register. Available from: https://www.landlaeknir.is/tolfraedi-og-rannsoknir/gagna sofn/gagnasafn/item 12455/Lyfjagagnagrunnur-(PrescriptionMedicines-Register. Accessed October 10, 20210.

99. Stovring H, Pottegard A, Hallas J. Refining estimates of prescription durations by using observed covariates in pharmacoepidemiological databases: an application of the reverse waiting time distribution. Pharmacoepidemiol Drug Saf. 2017;26 (8):900-908.

100. Stovring H, Pottegard A, Hallas J. Determining prescription durations based on the parametric waiting time distribution. Pharmacoepidemiol Drug Saf. 2016;25(12):1451-1459. doi: $10.1002 /$ pds.4114

101. Thrane JM, Stovring H, Hellfritzsch M, Hallas J, Pottegard A. Empirical validation of the reverse parametric waiting time distribution and standard methods to estimate prescription durations for warfarin. Pharmacoepidemiol Drug Saf. 2018;27(9):10111018. doi: $10.1002 /$ pds.4581

102. Laugesen K, Stovring H, Hallas J, et al. Prescription duration and treatment episodes in oral glucocorticoid users: application of the parametric waiting time distribution. <![CDATA [Clinical Epidemiology]]>. 2017;9:591-600. doi:10.2147/ CLEP.S148671

103. Schmidt M, Hallas J, Laursen M, Friis S. Data Resource Profile: danish online drug use statistics (MEDSTAT). Int $J$ Epidemiol. 2016;45(5):1401-1402g. doi:10.1093/ije/dyw116

104. Fimea. Consumption information. Available from: https://www. fimea.fi/web/en/databases_and_registers/consumption-informa tion. Accessed November 24, 2020.

105. Socialstyrelsen. Statistical database for medicinal products. Available from: https://sdb.socialstyrelsen.se/if_lak/val.aspx. Accessed November 26, 2020

106. Folkehelseinstituttet. Welcome to the Norwegian Prescription Database. Available from: http://www.norpd.no/. Accessed November 24, 2020.

107. Lund JL, Richardson DB, Stürmer T. The active comparator, new user study design in pharmacoepidemiology: historical foundations and contemporary application. Current Epidemiol Rep. 2015;2(4):221-228. doi:10.1007/s40471-015-0053-5

108. Helweg-Larsen K. The Danish Register of Causes of Death. Scand J Public Health. 2011;39(7 Suppl):26-29.

109. Brooke HL, Talbäck M, Hörnblad J, et al. The Swedish cause of death register. Eur J Epidemiol. 2017;32(9):765-773.

110. Helsedata. Dødsårsaksregisteret (DÅR). Available from: https:// helsedata.no/no/forvaltere/folkehelseinstituttet/dodsarsaksregis teret/. Accessed October 23, 2020.
111. Directorate of Health. Causes of Death Register. Available from: https:/www.landlaeknir.is/tolfraedi-og-rannsoknir/gagnasofn/gag nasafn/item15417/Danarmeinaskra-(Causes-of-Death-Register.). Accessed October 23, 2020.

112. Norwegian Institute of Public Health. Guidance for reference. Available from: https://www.fhi.no/en/more/access-to-data/ retningslinje-for-referanse/. Accessed May 11, 2021.

113. Directorate of Health. Registers and health information. Available from: https:/www.landlaeknir.is/english/registersandhealthinfor mation/. Accessed May 11, 2021.

114. The Swedish Research council. Registers in Sweden. Available from: https:/www.registerforskning.se/en/registers-in-sweden/. Accessed May 11, 2021.

115. FINNGEN. Health registries. Available from: https://www.finn gen.fi/en/health-registries. Accessed May 11, 2021.

116. Gissler M, Haukka J. Finnish health and social welfare registers in epidemiological research. Norsk Epidemiologi. 2004;14 (1):113-120.

117. Helsedata. Finn helsedata. Available from: https://www.helsedata. no/. Accessed May 11, 2021.

118. Baadsgaard M, Quitzau J. Danish registers on personal income and transfer payments. Scand J Public Health. 2011;39(7 Suppl):103-105.

119. Petersson F, Baadsgaard M, Thygesen LC. Danish registers on personal labour market affiliation. Scand J Public Health. 2011;39(7 Suppl):95-98.

120. Jensen VM, Rasmussen AW. Danish Education Registers. Scand J Public Health. 2011;39(7 Suppl):91-94.

121. Statistics Iceland. Available from: https:/www.statice.is/. Accessed May 11, 2021.

122. Statistic Sweden. Finding statistics. Available from: https://www. scb.se/en/finding-statistics/. Accessed May 11, 2021.

123. Ludvigsson JF, Svedberg P, Olén O, Bruze G, Neovius M. The longitudinal integrated database for health insurance and labour market studies (LISA) and its use in medical research. Eur $J$ Epidemiol. 2019;34(4):423-437.

124. Blenstrup LT, Knudsen LB. Danish registers on aspects of reproduction. Scand J Public Health. 2011;39(7 Suppl):79-82.

125. Sørensen HT, Pedersen L, Jørgensen J, Ehrenstein V. Danish clinical quality databases - an important and untapped resource for clinical research. Clin Epidemiol. 2016;8:425-427.

126. Emilsson L, Lindahl B, Köster M, Lambe M, Ludvigsson JF. Review of 103 Swedish Healthcare Quality Registries. J Intern Med. 2015;277(1):94-136.

127. Christensen AI, Lau CJ, Kristensen PL, et al. The Danish National Health Survey: study design, response rate and respondent characteristics in 2010, 2013 and 2017. Scand J Public Health. 2020;1403494820966534.

128. Borodulin K, Tolonen H, Jousilahti P, et al. Cohort Profile: the National FINRISK Study. Int J Epidemiol. 2018;47(3):696-696i.

129. Swedish National Data service. National public health survey, Health on equal terms. Available from: https://snd.gu.se/en/catalo gue/collection/national-public-health-survey-health-on-equalterms. Accessed May 11, 2021.

130. Stattin M, Järvholm B. Occupation, work environment, and disability pension: a prospective study of construction workers. Scand J Public Health. 2005;33(2):84-90.

131. Tjønneland A, Olsen A, Boll K, et al. Study design, exposure variables, and socioeconomic determinants of participation in Diet, Cancer and Health: a population-based prospective cohort study of 57,053 men and women in Denmark. Scand J Public Health. 2007;35(4):432-441.

132. Pedersen DA, Larsen LA, Nygaard M, et al. The Danish Twin Registry: an Updated Overview. Twin Res Human Genetics. 2019;22(6):499-507. 
133. Olsen J, Melbye M, Olsen SF, et al. The Danish National Birth Cohort-its background, structure and aim. Scand J Public Health. 2001;29(4):300-307.

134. Christensen DH, Nicolaisen SK, Berencsi K, et al. Danish Centre for Strategic Research in Type 2 Diabetes (DD2) project cohort of newly diagnosed patients with type 2 diabetes: a cohort profile. BMJ Open. 2018;8(4):e017273.

135. Nilsen TS, Knudsen GP, Gervin K, et al. The Norwegian Twin Registry from a public health perspective: a research update. Twin Res Human Genetics. 2013;16(1):285-295.

136. Hammarström A, Janlert U. Cohort profile: the northern Swedish cohort. Int J Epidemiol. 2012;41(6):1545-1552.

137. Zagai U, Lichtenstein P, Pedersen NL, Magnusson PKE. The Swedish Twin Registry: content and management as a research infrastructure. Twin Res Human Genetics. 2019;22(6):672-680.

138. Magnus P, Irgens LM, Haug K, Nystad W, Skjaerven R, Stoltenberg C. Cohort profile: the Norwegian Mother and Child Cohort Study (MoBa). Int J Epidemiol. 2006;35(5):1146-1150.

139. Kaprio J. The Finnish Twin Cohort Study: an update. Twin Res Human Genetics. 2013;16(1):157-162.

140. Erichsen R, Lash TL, Hamilton-Dutoit SJ, Bjerregaard B, Vyberg M, Pedersen L. Existing data sources for clinical epidemiology: the Danish National Pathology Registry and Data Bank. Clin Epidemiol. 2010;2:51-56.

141. Pedersen OB, Erikstrup C, Kotzé SR, et al. The Danish Blood Donor Study: a large, prospective cohort and biobank for medical research. Vox Sang. 2012;102(3):271.

142. Sørensen E, Christiansen L, Wilkowski B, et al. Data resource profile: the Copenhagen Hospital Biobank (CHB). Int $J$ Epidemiol. 2020.

143. Kringelbach TM, Glintborg B, Hogdall EV, Johansen JS, Hetland ML. Identification of new biomarkers to promote personalised treatment of patients with inflammatory rheumatic disease: protocol for an open cohort study. BMJ Open. 2018;8(2):e019325.

144. Biobank Sverige. Guide to Biobanks in Sweden. Available from: https://biobanksverige.se/wp-content/uploads/k7-guide-to-bio banks-in-sweden.pdf. Accessed May 07, 2021.

145. Zika E, Paci D, Schulte in den Bäumen T, et al. Biobanks in Europe: prospects for Harmonisation and Networking. Available from: file:/// C:/Users/au193513/Downloads/jrc57831.pdf. Accessed May 11, 2021.

146. Voutilainen M. Epidemiological trends in oesophageal cancer in the Nordic countries. Scand J Gastroenterol. 2008;43(3):323-327.

147. Lundberg FE, Andersson TM, Lambe M, et al. Trends in cancer survival in the Nordic countries 1990-2016: the NORDCAN survival studies. Acta Oncologica (Stockholm, Sweden). 2020;59 (11):1266-1274.
148. Klint A, Engholm G, Storm HH, et al. Trends in survival of patients diagnosed with cancer of the digestive organs in the Nordic countries 1964-2003 followed up to the end of 2006. Acta Oncologica (Stockholm, Sweden). 2010;49(5):578-607.

149. Tryggvadóttir L, Gislum M, Bray F, et al. Trends in the survival of patients diagnosed with breast cancer in the Nordic countries 1964-2003 followed up to the end of 2006. Acta Oncologica (Stockholm, Sweden). 2010;49(5):624-631.

150. Engholm G, Hakulinen T, Gislum M, et al. Trends in the survival of patients diagnosed with kidney or urinary bladder cancer in the Nordic countries 1964-2003 followed up to the end of 2006. Acta Oncologica (Stockholm, Sweden). 2010;49(5):655-664.

151. Bray F, Engholm G, Hakulinen T, et al. Trends in survival of patients diagnosed with cancers of the brain and nervous system, thyroid, eye, bone, and soft tissues in the Nordic countries 1964-2003 followed up until the end of 2006. Acta Oncologica (Stockholm, Sweden). 2010;49(5):673-693.

152. Møller B, Fekjaer H, Hakulinen T, et al. Prediction of cancer incidence in the Nordic countries up to the year 2020. Eur $J$ Cancer Prev. 2002;11(Suppl 1):S1-96.

153. Pukkala E, Martinsen JI, Lynge E, et al. Occupation and cancer follow-up of 15 million people in five Nordic countries. Acta Oncologica (Stockholm, Sweden). 2009;48(5):646-790.

154. University of Bergen. SCAN-AED: Nordic register-based study of antiepileptic drugs in pregnancy. Available from: https://www. uib.no/en/rg/epilepsy/123035/scan-aed-nordic-register-basedstudy-antiepileptic-drugs-pregnancy. Accessed June 16, 2021. Accessed May 20, 2021.

155. Maret-Ouda J, Tao W, Wahlin K, Lagergren J. Nordic registrybased cohort studies: possibilities and pitfalls when combining Nordic registry data. Scand J Public Health. 2017;45 (17_suppl):14-19.

156. NordForsk. Available from: https://www.nordforsk.org/. Accessed November 29, 2020.

157. NordForsk. Nordic Microdata Access Network (NordMAN). Available from: https://old.nordforsk.org/en/programmes-and-pro jects/projects/nordic-microdata-access-network-nordman. Accessed November 11, 2020.

158. NordForsk. A vission of a Nordic secure digital infrastructure for health data: the Nordic Commons. Available from: http://norden. diva-portal.org/smash/get/diva2:1376735/FULLTEXT01.pdf. Accessed March 17, 2021.

159. Ludvigsson JF, Håberg SE, Knudsen GP, et al. Ethical aspects of registry-based research in the Nordic countries. Clin Epidemiol. 2015;7:491-508
Clinical Epidemiology

\section{Publish your work in this journal}

Clinical Epidemiology is an international, peer-reviewed, open access, online journal focusing on disease and drug epidemiology, identification of risk factors and screening procedures to develop optimal preventative initiatives and programs. Specific topics include: diagnosis, prognosis, treatment, screening, prevention, risk factor modification, systematic reviews, risk \& safety of medical interventions, epidemiology \& biostatistical methods, and evaluation of guidelines, translational medicine, health policies \& economic evaluations. The manuscript management system is completely online and includes a very quick and fair peer-review system, which is all easy to use. 